\title{
Efficiency of Thin-Film CdS/CdTe Solar Cells
}

\author{
Leonid Kosyachenko \\ Chernivtsi National University \\ Ukraine
}

\section{Introduction}

Over the last two decades, polycrystalline thin-film CdS/CdTe solar cells fabricated on glass substrates have been considered as one of the most promising candidates for large-scale applications in the field of photovoltaic energy conversion (Surek, 2005; Goetzberger et al., 2003; Romeo et al., 2004). CdTe-based modules have already made the transition from pilot scale development to large manufacturing facilities. This success is attributable to the unique physical properties of CdTe which make it ideal for converting solar energy into useful electricity at an efficiency level comparable to traditional Si technologies, but with the use of only about $1 \%$ of the semiconductor material required by Si solar cells.

To date, the record efficiencies of laboratory samples of CdS/CdTe solar cells and large-area modules are $\sim 16.5 \%$ and less than $10 \%$, respectively (Britt \& Ferekides, 1993; Hanafusa et al., 1997; Meyers \& Albright, 2000; Wu et al., 2001; Hanafusa et al., 2001; Bonnet, 2003). Thus, even the record efficiency of such type solar cells is considerable lower than the theoretical limit of $28-30 \%$ (Sze, 1981). Next challenge is to improve the performance of the modules through new advances in fundamental material science and engineering, and device processing. Further studies are required to reveal the physical processes determining the photoelectric characteristics and the factors limiting the efficiency of the devices.

In this chapter, we present the results of studying the losses accompanying the photoelectric conversion in the thin-film CdS/CdTe heterostructures and hence reducing the efficiency of modules on glass substrate coated with a semitransparent ITO or $\mathrm{SnO}_{2}$ conducting layer. We discuss the main parameters of the material used and the barrier structure determining the photoelectric conversion efficiency in CdS/CdTe solar cell: (i) the width of the space-charge region, (ii) the lifetime of minority carriers, (iii) their diffusion length and drift length, (iv) the surface recombination velocity, and (v) the thickness of the CdTe absorber layer.

Among other factors, one of the important characteristics determining the efficiency of a solar cell is the spectral distribution of the quantum efficiency which accounts for the formation of the drift and diffusion components of the photocurrent and ultimately the short-circuit current density. In the paper particular attention is given to this aspect of solar cell. We demonstrate the possibility to describe quantitatively the quantum efficiency spectra of the thin-film CdS/CdTe solar cells taking into account the recombination losses at the CdS-CdTe interface and the back surface of the CdTe absorber layer.

Charge collection efficiency in thin-film CdS/CdTe solar cells are also discussed taking into consideration losses caused by a finite thickness of the p-CdTe layer, recombination losses at the front and back surfaces as well as in the space-charge region. The dependences of the 
drift and diffusion components of short-circuit current on the uncompensated acceptor concentration, charge carrier lifetime, recombination velocities at the interfaces are evaluated and discussed.

The mechanism of the charge transport in the CdS/CdTe heterostructure determining the other photoelectric parameters of the solar cell, namely, the open-circuit voltage and fill factor is also considered. It is shown that the above-barrier (diffusion) current of minority carriers is important only at high bias voltage, and the dominant charge transport mechanism is the generation-recombination occurring in the depletion layer. The observed $I-V$ characteristics in the dark and the light are described mathematically in the context of the Sah-Noyce-Shockley theory.

\section{Spectral distribution of quantum efficiency of $\mathrm{CdS} / \mathrm{CdTe}$ heterostructure}

In this section we will describe mathematically the spectral distribution of quantum efficiency of the thin-film CdS/CdTe solar cells taking into account the main parameters of the material used and the barrier structure, recombination in the space-charge region, at the CdS-CdTe interface and the back surface of the CdTe absorber layer.

Quantum efficiency $\eta_{\text {ext }}$ is the ratio of the number of charge carriers collected by the solar cell to the number of photons of a given energy (wavelength $\lambda$ ) shining on the solar cell. Quantum efficiency relates to the response (A/W) of a solar cell to the various wavelengths in the spectrum. In the case of monochromatic radiation (narrow spectral range) $\eta_{\text {ext }}(\lambda)$ relates to the radiation power $P_{\text {opt }}$ and the photocurrent $I_{\mathrm{ph}}$ by formula

$$
\eta_{\mathrm{ext}}(\lambda)=\frac{I_{\mathrm{ph}} / q}{P_{\mathrm{opt}} / h v},
$$

where $q$ is the electronic charge, $h v$ is the photon energy.

\subsection{Experimental}

Fig. 1(a) shows the quantum efficiency spectra of the CdS/CdTe solar cell taken at different temperatures. The substrates used for the development of thin film layers were glass plates coated with a semitransparent ITO $\left(\mathrm{SnO}_{2}+\mathrm{In}_{2} \mathrm{O}_{3}\right)$ layer. The window layer $\mathrm{CdS}(\sim 0.1 \mu \mathrm{m})$ was developed by chemical bath deposition (CBD); the absorber layer CdTe $(1-3 \mu \mathrm{m})$ was deposited on top of CdS by close-space sublimation (CSS) (Mathew et al., 2007). Non-rectifying ohmic contact to the CdTe layer was fabricated by sputtering $\mathrm{Ni}$ in vacuum after bombarding the CdTe surface by Ar ions with energy $\sim 500 \mathrm{eV}$. The electrical characteristics of two neighboring $\mathrm{Ni}$ contacts on the CdTe surface were linear over the entire range of measured currents.

The spectral characteristics of the samples in the 300-900 $\mathrm{nm}$ range were recorded with a photoresponse spectral system equipped with a quartz halogen lamp. The spectral distribution of the photon flux at the outlet slit of the system was determined using a calibrated Si photodiode.

As can be seen from Fig. 1(a), compared with the literature data, the measured curves seem to reflect the most common features of the corresponding spectral curves for these devices (Sites et al., 2001; McCandless et al., 2003; Ferekides et al., 2004).

In the long-wavelength region, the spectra are restricted to the value $\lambda_{g}$ corresponding to the band gap of CdTe which is equal to $1.46 \mathrm{eV}$ at $300 \mathrm{~K}\left(\lambda_{g}=h c / E_{g}=845 \mathrm{~nm}\right)$. In the short- 

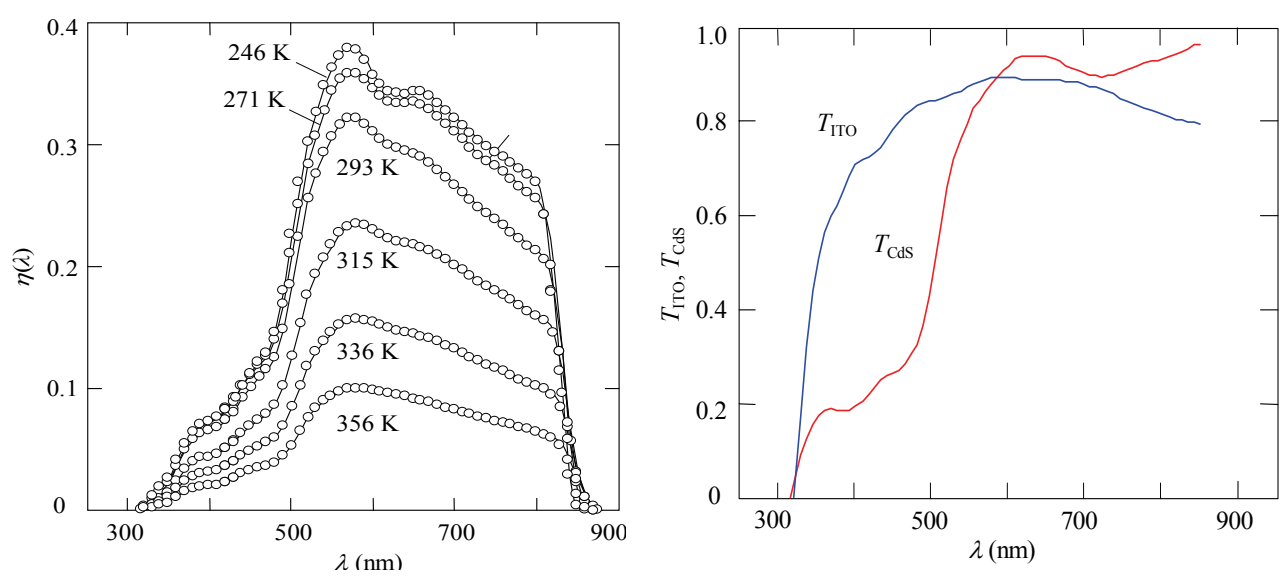

Fig. 1. (a) Spectral distribution of the quantum efficiency of CdS/CdTe device measured at different temperatures. (b) The transmission curves of the ITO coated glass $\left(T_{\text {ITO}}\right)$ and the CdS layer $\left(T_{\mathrm{CdS}}\right)$ as a functions of the wavelength $\lambda$.

wavelength side, the quantum efficiency decays due to the lower transmission through the thin film layers: CdS in the range $\lambda<500-520 \mathrm{~nm}$ and ITO at $\lambda<350 \mathrm{~nm}$ (Fig. 1(b)).

The external quantum efficiency $\eta_{\text {ext }}$ is related with the quantum efficiency of photoelectric conversion in the CdTe absorber layer, the transmission of the glass plate coated by ITO, $T_{\mathrm{ITO}}$, and the transmission of the CdS layer, $T_{\mathrm{Cd}}$, by the expression:

$$
\eta_{\mathrm{ext}}=T_{\mathrm{ITO}} T_{\mathrm{CdS}} \eta_{\text {int }}
$$

where $\eta_{\text {int }}$ is the ratio of photogenerated carriers collected to the photon flux that arrives at the CdTe absorber layer.

In order to describe the external quantum efficiency spectrum $\eta_{\text {ext }}$ we used the measured spectral dependences $T_{\mathrm{ITO}}(\lambda)$ and $T_{\mathrm{CdS}}(\lambda)$ shown in Fig. $1(\mathrm{~b})$. The quantum efficiency $\eta_{\text {int }}$ will be determined in the following by considering the photoelectric processes in the diode structure.

\subsection{Width of the space-charge region and energy diagram of thin-film $\mathrm{CdS} / \mathrm{CdTe}$ heterostructure}

One of the parameters of a solar cell that determines the electrical and photoelectric characteristics is the width of the space-charge region $W$. It is known that in CdS/CdTe solar cells only the CdTe is contributing to the light-to-electric energy conversion and the window layer CdS absorbs light in the range $\lambda<500-520 \mathrm{~nm}$ thereby reducing the photocurrent. Therefore in numerous papers where the energy band diagram of a CdS/CdTe junction is discussed a band bending in the CAS layer (and hence a depletion layer) is not depicted (see, for example, Goetzberger et al, 2003; Birkmire \& Eser, 1997; Fritsche et al., 2001). Analyzing the efficiency of CdS/CdTe solar cells, however, one is forced to assume the

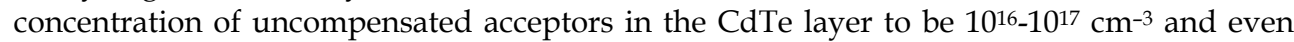
higher (a narrow depletion layer is assumed). It may appear that the latter comes into conflict with the commonly accepted model of CdS/CdTe as a sharply asymmetrical p-n heterojunction. In fact, this is not the case because the width of space-charge region of a 
diode structure is determined by the concentration of uncompensated impurity $\left(N_{d}-N_{a}\right.$ for $\mathrm{CdS}$ ) rather than by the free carrier concentration ( $n$ for $n-C d S$ ). These values coincide only in an uncompensated semiconductor with a shallow donor level whose ionization energy is less than the average thermal energy $k T$. However, the CdS layer contains a large number of background impurities (defects) of donor and acceptor types, which introduce in the band gap both shallow and deep levels. The effect of self-compensation is inherent in this material: a donor impurity introduces p-type compensating defects in just as high concentration as needed to annihilate virtually the electrical activity of donor (Desnica et al, 1999). As a result, CdS is a compensated semiconductor to a greater or lesser extent. In this case, the Fermi level is known to be pinned by the level (so-called pinning effect), which is partially compensated with the degree of compensation $N_{\mathrm{a}} / N_{\mathrm{d}}$ close to 0.5 (if $N_{\mathrm{a}} / N_{\mathrm{d}}=0.5$ the Fermi level exactly coincides with the deep impurity level) (Mathew et al., 2007). Assuming $N_{\mathrm{d}}-N_{\mathrm{a}}$ equal to $n$, one can make serious mistake concerning the determination of the space-charge region width in CdS. Thus, due to a large number of background impurities (defects), the uncompensated donor concentration in the CdS layer can be much higher than the electron concentration in the conduction band of CdS. When such is the case the depletion layer of the CdS/CdTe diode structure is virtually located in the p-CdTe layer even in the case of a CdS layer with comparable high-resistivity (Fig. 2). This is identical to the case of an asymmetric abrupt p-n junction or a Schottky diode; the width of the spacecharge region in the CdS/CdTe heterojunction can be expressed as (Sze, 1981):

$$
\begin{gathered}
\varphi(x, V)=\left(\varphi_{\mathrm{o}}-q V\right)\left(1-\frac{x}{W}\right)^{2}, \\
W=\sqrt{\frac{2 \varepsilon \varepsilon_{o}\left(\varphi_{\mathrm{o}}-q V\right)}{q^{2}\left(N_{\mathrm{a}}-N_{\mathrm{d}}\right)}},
\end{gathered}
$$

where $\varepsilon_{\mathrm{o}}$ is the electric constant, $\varepsilon$ is the dielectric constant of the semiconductor, $\varphi_{\mathrm{o}}=q V_{\mathrm{bi}}$ is the barrier height at the semiconductor side ( $V_{\mathrm{bi}}$ is the built-in potential), $V$ is the applied voltage, and $N_{\mathrm{a}}-N_{\mathrm{d}}$ is the uncompensated acceptor concentration in the CdTe layer.

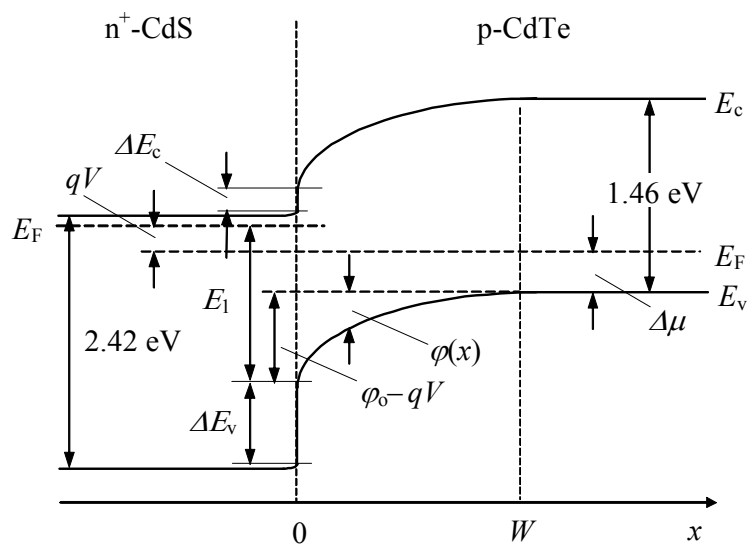

Fig. 2. Energy diagram of $\mathrm{n}-\mathrm{CdS} / \mathrm{p}-\mathrm{CdTe}$ heterojunction for forward-bias condition. $\Delta E_{\mathrm{c}}$ and $\Delta E_{\mathrm{v}}$ show the discontinuities (offsets) of the conduction and valence bands, respectively. 


\subsection{Theoretical description of quantum efficiency}

The quantum efficiency $\eta_{\text {int }}$ can be found from the continuity equation which is solved using the boundary conditions. The exact solution of this equation with account made for the drift and diffusion components as well as surface recombination at the CdS/CdTe interface leads to rather cumbersome and non-visual expression for $\eta_{\text {int }}$ (Lavagna et al, 1977):

$$
\eta_{\text {int }}=\frac{1+\frac{S}{D_{\mathrm{n}}} \exp \left(-\frac{W^{2}}{W_{\mathrm{o}}^{2}}\right)\left[A(\alpha)-D_{1}(\alpha)\right]}{1+\frac{S}{D_{\mathrm{n}}} \exp \left(-\frac{W^{2}}{W_{\mathrm{o}}^{2}}\right) B}-\frac{\exp (-\alpha W)}{1+\alpha L_{\mathrm{n}}}-D_{2}(\alpha),
$$

where $S$ is the velocity of recombination at the front surface, $D_{\mathrm{n}}$ is the diffusion coefficient of electrons, and $\left.L_{\mathrm{n}}=\left(\tau_{\mathrm{n}} D_{\mathrm{n}}\right)^{1 / 2}\right)$ is the electron diffusion length. The values $A, B, D_{1}$ and $D_{2}$ in Eq. (5) are the integral functions of the absorption coefficient $\alpha$, the width of the depletion layer $W$ and the effective Debye length $W_{\mathrm{o}}=\left(\varepsilon \varepsilon_{\mathrm{o}} k T / q^{2}\left(N_{\mathrm{a}}-N_{\mathrm{d}}\right)\right)^{1 / 2}$.

Eq. (5) may be essentially simplified. At the boundary between the depletion and neutral regions $(x=W)$, the photogenerated electrons are entrained by strong electric field and, hence, one may put $\Delta n(W)=0$. This means that the terms $D_{1}$ and $D_{2}$ in Eq. (5) can be neglected. When calculating the values $A(\alpha)$ and $B$, one can replace the integration by multiplication of the maximum value of the integrands by their "half-widths". The halfwidths are determined by the value of $x$ at the point where the value of the integrand is smaller than the peak value by a factor of $e=2.71$.

After such simplification, instead of Eq. (5) one can write (Kosyachenko et al., 1999):

$$
\eta_{\mathrm{int}}=\frac{1+\frac{S}{D_{\mathrm{n}}}\left(\alpha+\frac{2}{W} \frac{\kappa_{\mathrm{o}}-q V}{k T}\right)^{-1}}{1+\frac{S}{D_{\mathrm{n}}}\left(\frac{2}{W} \frac{\varphi_{\mathrm{o}}-q V}{k T}\right)^{-1}}-\frac{\exp (-\alpha W)}{1+\alpha L_{\mathrm{n}}} .
$$

Comparison of the dependences $\eta_{\text {int }}(\lambda)$ calculated in a wide range of the parameters and the absorption coefficient $\alpha$ shows that equation (6) approximates the exact equation (5) very well (Kosyachenko, 2006).

It should be emphasized that Eqs. (5) and (6) do not take into consideration the recombination at the back surface of the CdTe layer (when deriving Eq. (5) the condition $\Delta n$ $=0$ at $x \rightarrow \infty$ was used) which can result in significant losses in the case of a thin CdTe layer with large diffusion length of the minority carriers. However, we can use the Eq. (5) to find the expression for the drift component of the photoelectric quantum yield. This can be done as follows.

In the absence of recombination at the front surface, equation (6) transforms into the known Gartner formula (Gartner, 1959)

$$
\eta_{\text {int }}=1-\frac{\exp (-\alpha W)}{1+\alpha L_{\mathrm{n}}}
$$

which ignores recombination at the back surface of the CdTe layer. In this case, the photoelectric quantum yield caused by processes in the space-charge region is equal to the 
absorptivity of this layer, that is, $1-\exp (-\alpha W)$. Thus, subtracting the term $1-\exp (-\alpha W)$ from the right side of Eq. (7), we obtain the expression for the diffusion component of the photoelectric quantum yield

$$
\eta_{\text {diff }}^{o}=\exp (-\alpha W) \frac{\alpha L_{n}}{1+\alpha L_{n}},
$$

which, of course, ignores recombination at the back surface of the CdTe layer. Subtracting $\exp (-\alpha W) \alpha L_{n} /\left(1+\alpha L_{n}\right)$ from the right side of Eq. (6) we come to the expression for the drift component of the photoelectric quantum yield taking into account surface recombination at the CdS-CdTe interface:

$$
\eta_{\text {drift }}=\frac{1+\frac{S}{D_{\mathrm{n}}}\left(\alpha+\frac{2}{W} \frac{\varphi_{\mathrm{o}}-q V}{k T}\right)^{-1}}{1+\frac{S}{D_{\mathrm{n}}}\left(\frac{2}{W} \frac{\varphi_{\mathrm{o}}-q V}{k T}\right)^{-1}}-\exp (-\alpha W)
$$

For the diffusion component of the photoelectric quantum yield that takes into account surface recombination at the back surface of the CdTe layer, we can use the exact expression obtained for the p-layer in a p-n junction solar cell (Sze, 1981)

$$
\begin{aligned}
& \eta_{\text {dif }}=\frac{\alpha L_{\mathrm{n}}}{\alpha^{2} L_{\mathrm{n}}^{2}-1} \exp (-\alpha W) \times \\
& \times\left\{\alpha L_{\mathrm{n}}-\frac{\frac{S_{\mathrm{b}} L_{\mathrm{n}}}{D_{\mathrm{n}}}\left[\cosh \left(\frac{d-W}{L_{\mathrm{n}}}\right)-\exp (-\alpha(d-W))\right]+\sinh \left(\frac{d-W}{L_{\mathrm{n}}}\right)+\alpha L_{\mathrm{n}} \exp (-\alpha(d-W))}{\frac{S_{\mathrm{b}} L_{\mathrm{n}}}{D_{\mathrm{n}}} \sinh \left(\frac{d-W}{L_{\mathrm{n}}}\right)+\cosh \left(\frac{d-W}{L_{\mathrm{n}}}\right)}\right\}
\end{aligned}
$$

where $d$ is the thickness of the CdTe absorber layer, $S_{\mathrm{b}}$ is the recombination velocity at the back surface of the CdTe layer.

The total quantum yield of photoelectric conversion in the CdTe absorber layer is the sum of the two components:

$$
\eta_{\text {int }}=\eta_{\text {drift }}+\eta_{\text {dif }}
$$

\subsection{Comparison of calculation results with experiment}

Fig. 3(a) shows the computed spectra of the external quantum efficiency $\eta_{\text {ext }}(\lambda)$ illustrating the effect of the uncompensated donor impurities in a CdS/CdTe heterojunction. In this calculation the absorption curve $\alpha(\lambda)$ was used from publication Toshifumi et al., 1993, the values of $S$ and $\tau_{n}$ were taken as $10^{7} \mathrm{~cm} / \mathrm{s}$ and $10^{-10} \mathrm{~s}$, respectively.

It can be seen from Fig. 3(a) that, as the uncompensated donor concentration varies, the shape of the $\eta_{\text {ext }}(\lambda)$ curves undergo significant changes. If the $N_{a}-N_{d}$ decreases from $10^{17} \mathrm{~cm}^{-3}$ to $10^{13} \mathrm{~cm}^{-3}$, the external quantum efficiency increases first and then decreases. The increase in $\eta_{\text {ext }}(\lambda)$ is due to the expansion of the depletion layer and, hence, to more efficient collection of photogenerated carriers from the bulk of the film. However, if the depletion 
(a)

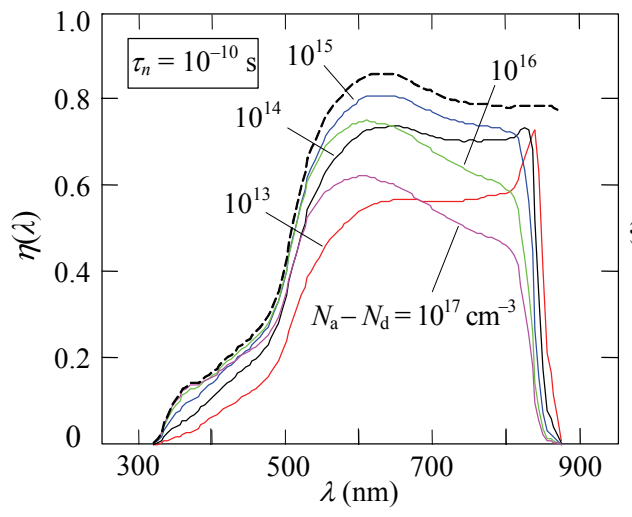

(b)

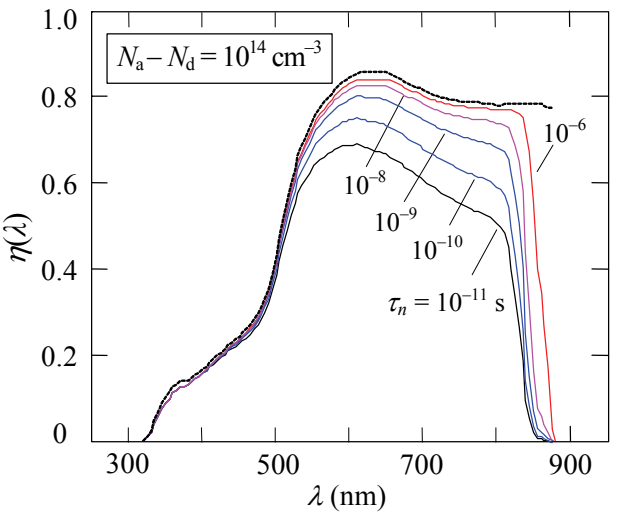

(c)

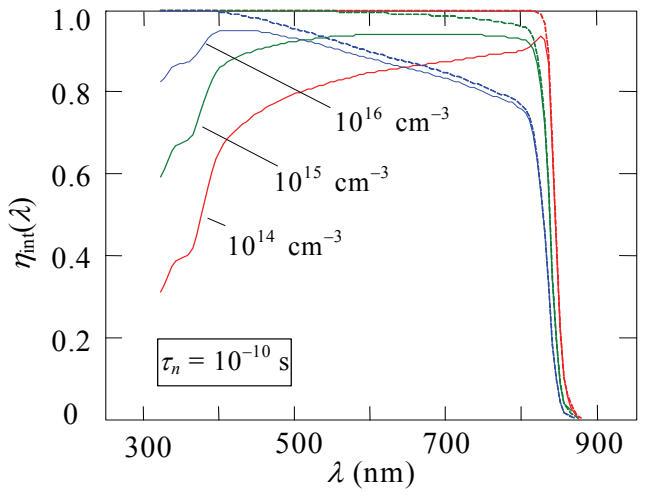

Fig. 3. (a) The external quantum efficiency spectra $\eta_{\text {ext }}$ calculated using equations.

(4),(9)-(11) at $\tau_{n}=10^{-10} \mathrm{~s}$ and different uncompensated acceptor concentrations $N_{\mathrm{a}}-N_{\mathrm{d}}$,

(b) at $N_{\mathrm{a}}-N_{\mathrm{d}}=10^{16} \mathrm{~cm}^{-3}$ and different electron lifetimes $\tau_{\mathrm{n}}$ and (c) the internal quantum efficiency spectra $\eta_{\text {int }}$ calculated at different uncompensated acceptor concentrations and surface recombination velocity $S=7 \times 10^{7} \mathrm{~cm} / \mathrm{s}$ (solid lines) and $S=0$ (dashed lines).

layer widens, the electric field becomes weaker which is favorable for the surface recombination. This effect is clearly demonstrated by the graphs for which $N_{\mathrm{a}}-N_{\mathrm{d}}$ is $10^{14}$ $\mathrm{cm}^{-3}$ and $10^{13} \mathrm{~cm}^{-3}$ : the surface recombination causes a significant decay with decreasing the wavelength. Evidently, the decay in photosensitivity in the $\lambda<400 \mathrm{~nm}$ region is also caused by absorption by the CdS layer and the conducting glass substrate. Absorption in the CdS layer masks the influence of surface recombination, however, that can be revealed in the spectra of "internal" quantum efficiency $\eta_{\text {int }}$ shown in Fig. 3(c). As seen, the recombination losses are significant for rather low concentration of uncompensated acceptors $10^{14}-10^{15} \mathrm{~cm}^{-3}$. As can be seen from Fig. 3(b), the variation in the carrier lifetime $\tau_{\mathrm{n}}$ has practically no influence on the spectral curves of the device $\left(N_{\mathrm{a}}-N_{\mathrm{d}}=10^{16} \mathrm{~cm}^{-3}\right)$ in the wavelength range $\lambda<500 \mathrm{~nm}$. This is because in this spectral range, the depth of penetration of photons $\alpha^{-1}\left(\alpha>10^{5} \mathrm{~cm}^{-1}\right)$ is equal to or even smaller than the width of the space-charge region $W$. 
Thus, only a small portion of the incident radiation is absorbed outside the space charge region and therefore the dependence of diffusion component of photocurrent on the electron lifetime is negligible.

On the other hand, in the wavelength range $\lambda>500 \mathrm{~nm}$ a considerable portion of the radiation is absorbed outside the space charge region and consequently as the electron lifetime increases the photoresponse also increases. When $N_{\mathrm{a}}-N_{\mathrm{d}}$ increases the effect of the electron lifetime increases and when $N_{\mathrm{a}}-N_{\mathrm{d}}$ decreases the effect of the electron lifetime becomes weaker so that at $N_{\mathrm{a}}-N_{\mathrm{d}} \leq 10^{14} \mathrm{~cm}^{-3}$ the photosensitivity is practically independent of the electron lifetime except the long-wavelength edge of the spectrum. It follows from Fig. 3(a) and (b) that, by varying the values of $N_{\mathrm{a}}-N_{\mathrm{d}}$ and $\tau$, one can obtain the photosensitivity spectra of various shapes including those similar to the experimental curves shown in Fig. 1(a).

Fig. 4 illustrates the comparison of the calculated curves $\eta_{\text {ext }}(\lambda)$ using Eqs. (4),(9)-(11) with the measured spectrum taken at $300 \mathrm{~K}$ (we can not do it for other temperatures due to the lack of $\alpha$ values). The figure shows a quite good fit of the experimental data with the calculated values. Note that only the two adjustable parameters, the uncompensated acceptor concentration $N_{\mathrm{a}}-N_{\mathrm{d}}$ and electron lifetime $\tau_{\mathrm{n}}$, have been used to fit the calculation results with the experimental data and which were found to be $7 \times 10^{16} \mathrm{~cm}^{-3}$ and $8 \times 10^{-11} \mathrm{~s}$, respectively. As can be seen from Fig. 3(c), the surface recombination velocity is not relevant at such high uncompensated acceptor concentration owing to the effect of a high electric field.

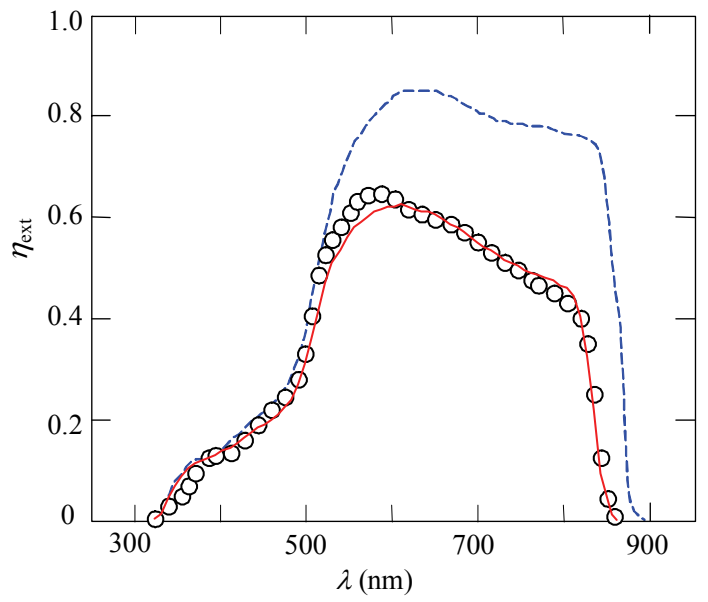

Fig. 4. Comparison of the measured (circles) and calculated (solid line) quantum efficiency spectrum $\eta_{\text {ext }}$ using Eqs. (4), (9)-(11) at $N_{\mathrm{a}}-N_{\mathrm{d}}=7 \times 10^{16} \mathrm{~cm}^{-3}, \tau_{\mathrm{n}}=8 \times 10^{-11} \mathrm{~s}$. The dashed line shows the spectrum of $100 \%$ internal efficiency $\left(N_{\mathrm{a}}-N_{\mathrm{d}}=10^{16} \mathrm{~cm}^{-3}, \tau_{\mathrm{n}}=10^{-6} \mathrm{~s}, d=100 \mu \mathrm{m}\right)$.

\section{Short-circuit current in $\mathrm{CdS} / \mathrm{CdTe}$ heterostructure}

The obtained expressions for quantum efficiency spectra can be used to calculate the shortcircuit current density $J_{\mathrm{sc}}$ which is a quantitative solar cell characteristic reflecting the charge collection efficiency under radiation. The calculations will be done for AM1.5 solar radiation using Tables ISO 9845-1:1992 (Standard ISO, 1992). If $\Phi_{\mathrm{i}}$ is the spectral radiation power density (in $\mathrm{mW} \mathrm{cm}^{-2} \mathrm{~nm}^{-1}$ ) and $h v$ is the photon energy (in $\mathrm{eV}$ ), the spectral density of the incident photon flux is $\Phi_{\mathrm{i}} / h v_{\mathrm{i}}\left(\right.$ in s $\left.^{-1} \mathrm{~cm}^{-2}\right)$, and then 


$$
J_{\mathrm{sc}}=q \sum_{i} \eta_{\mathrm{int}}(\lambda) \frac{\Phi_{\mathrm{i}}(\lambda)}{h v_{\mathrm{i}}} \Delta \lambda
$$

where $\Delta \lambda_{i}$ is the wavelength range between the neighboring values of $\lambda_{i}$ (the photon energy $\left.h v_{\mathrm{i}}\right)$ in the table and the summation is over the spectral range $\lambda<\lambda_{\mathrm{g}}=h c / E_{\mathrm{g}}$.

\subsection{The drift component of the short-circuit current}

Let us first consider the drift component of the short-circuit current density $J_{\text {drift }}$ using Eq. (12).

Fig. 5 shows the calculation results for $J_{\text {drift }}$ depending on the space-charge region width $W$. In the calculations, it was accepted $\varphi_{\mathrm{o}}-q V=1 \mathrm{eV}, S=10^{7} \mathrm{~cm} / \mathrm{s}$ (the maximum possible velocity of surface recombination) and $S=0$. The Eq. (9) was used for $\eta_{\text {int }}(\lambda)$.

Important practical conclusions can be made from the results presented in the figure.

If $S=0$, the short-circuit current gradually increases with widening of $W$ and approaches a maximum value of $J_{\text {drift }}=28.7 \mathrm{~mA} / \mathrm{cm}^{2}$ at $W>10 \mu \mathrm{m}$ (the value $J_{\text {drift }}=28.7 \mathrm{~mA} / \mathrm{cm}^{2}$ is obtained from equation (12) at $\eta_{\text {drift }}=1$ ).

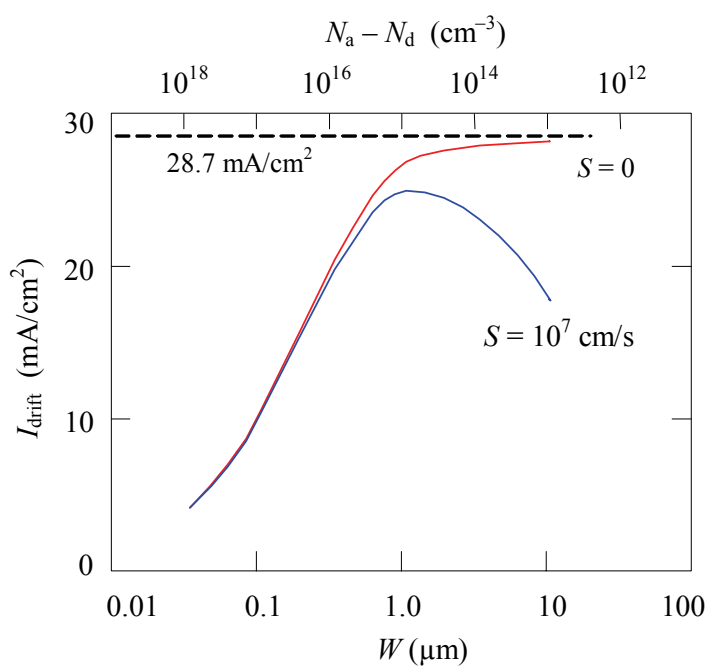

Fig. 5. Drift component of the short-circuit current density $J_{\text {drift }}$ of a CdTe-based solar cell as a function of the space-charge region width $W$ (the uncompensated acceptor concentration $N_{\mathrm{a}}-N_{\mathrm{d}}$ ) calculated for the surface recombination velocities $S=10^{7} \mathrm{~cm} / \mathrm{s}$ and $S=0$.

Such result should be expected because the absorption coefficient $\alpha$ in CdTe steeply increases in a narrow range $h v \approx E_{\mathrm{g}}$ and becomes higher than $10^{4} \mathrm{~cm}^{-1}$ at $h v>E_{\mathrm{g}}$. As a result, the penetration depth of photons $\alpha^{-1}$ is less than $\sim 1 \mu \mathrm{m}$ throughout the entire spectral range and in the absence of surface recombination, all photogenerated electron-hole pairs are separated by the electric field acting in the space-charge region.

Surface recombination decreases the short-circuit current only in the case if the electric field in the space-charge region is not strong enough. The electric field decreases as the spacecharge region widens, i.e. when the uncompensated acceptor concentration $N_{\mathrm{a}}-N_{\mathrm{d}}$ decreases. One can see from Fig. 5 that the influence of surface recombination at $N_{\mathrm{a}}-N_{\mathrm{d}}=10^{14}-10^{15} \mathrm{~cm}^{-3}$ is quite significant. However, as $N_{a}-N_{d}$ increases and consequently the electric field strength becomes stronger, the influence of surface recombination becomes 
weaker, and at $N_{\mathrm{a}}-N_{\mathrm{d}} \geq 10^{16} \mathrm{~cm}^{-3}$ the effect is virtually eliminated. However in this case, the short-circuit current density decreases with increasing $N_{\mathrm{a}}-N_{\mathrm{d}}$ because a significant portion of radiation is absorbed outside the space-charge region.

It should be noted that the fabrication of the $\mathrm{CdTe} / \mathrm{CdS}$ heterostructure is typically completed by a post-deposition heat treatment. The annealing enables grain growth, reduces defect density in the films, and promotes the interdiffusion between the CdTe and CdS layers. As a result, the CdS-CdTe interface becomes alloyed into the $\mathrm{CdTe}_{\mathrm{x}} \mathrm{S}_{1-\mathrm{x}}-\mathrm{CdS}_{\mathrm{y}} \mathrm{Te}_{1-\mathrm{y}}$ interface, and the surface recombination velocity is probably reduced to some extent (Compaan et al, 1999).

\subsection{The diffusion component of the short-circuit current}

In order to provide the losses caused by recombination at the CdS-CdTe interface and in the space-charge region at a minimum we will accept in this section $N_{\mathrm{a}}-N_{\mathrm{d}} \geq 10^{17} \mathrm{~cm}^{-3}$. On the other hand, to make the diffusion component of the short-circuit current $J_{\text {dif }}$ as large as possible, we will set $\tau_{\mathrm{n}}=3 \times 10^{-6}$ s, i.e. the maximum possible value of the electron lifetime in CdTe. Fig. 6(a) shows the calculation results of $J_{\text {dif }}$ (using Eqs. (10) and (12)) versus the CdTe layer thickness $d$ for the recombination velocity at the back surface $S=10^{7} \mathrm{~cm} / \mathrm{s}$ and $S=0$ (the thickness of the neutral part of the film is $d-W$ ).

One can see from Fig. 6(a) that for a thin CdTe layer (few microns) the diffusion component of the short-circuit current is rather small. In the case $S_{\mathrm{b}}=0$, the total charge collection in the neutral part (it corresponds to $J_{\text {dif }}=17.8 \mathrm{~mA} / \mathrm{cm}^{2}$ at $\eta_{\text {dif }}=1$ ) is observed at $d=15-20 \mu \mathrm{m}$. To reach the total charge collection in the case $S_{\mathrm{b}}=10^{7} \mathrm{~cm} / \mathrm{s}$, the CdTe thickness should be $50 \mu \mathrm{m}$ or larger. Bearing in mind that the thickness of a CdTe layer is typically between 2 and $10 \mu \mathrm{m}$, for $d=10,5$ and $2 \mu \mathrm{m}$ the losses of the diffusion component of the short-circuit current are 5, 9 and 19\%, respectively. The CdTe layer thickness can be reduced by shortening the electron lifetime $\tau_{\mathrm{n}}$ and hence the electron diffusion length $L_{\mathrm{n}}=\left(\tau_{\mathrm{n}} D_{\mathrm{n}}\right)^{1 / 2}$. However one does not forget that it leads to a significant decrease in the value of the diffusion current itself. This is illustrated in Fig. $6(\mathrm{~b})$, where the curve $J_{\mathrm{dif}}\left(\tau_{\mathrm{n}}\right)$ is plotted for a thick CdTe layer $(50 \mu \mathrm{m})$ taking into account the surface recombination velocity $S_{\mathrm{b}}=10^{7} \mathrm{~cm} / \mathrm{s}$. As it can be seen, shortening of the electron lifetime below $10^{-7}-10^{-6} \mathrm{~s}$ results in a significant lowering of the diffusion component of the short-circuit current density. Thus, when the space-charge region width is narrow, so that recombination losses at the

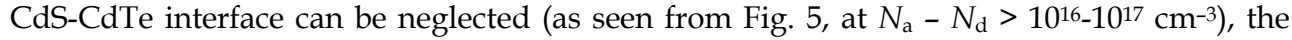
conditions for generation of the high diffusion component of the short-circuit current are $d>25-30 \mu \mathrm{m}$ and $\tau_{\mathrm{n}}>10^{-7-10-6} \mathrm{~s}$.

In connection with the foregoing the question arises why for total charge collection the thickness of the CdTe absorber layer $d$ should amount to several tens of micrometers. The value $d$ is commonly considered to be in excess of the effective penetration depth of the radiation into the CdTe absorber layer in the intrinsic absorption region of the semiconductor. As mentioned above, as soon as the photon energy exceeds the band gap of CdTe, the absorption coefficient $\alpha$ becomes higher than $10^{4} \mathrm{~cm}^{-1}$, i.e. the effective penetration depth of radiation $\alpha^{-1}$ becomes less than $10^{-4} \mathrm{~cm}=1 \mu \mathrm{m}$. With this reasoning, the absorber layer thickness is usually chosen at a few microns. However, all that one does not take into the account, is that the carriers arisen outside the space-charge region, diffuse into the neutral part of the CdTe layer penetrating deeper into the material. Carriers reached the back surface of the layer, recombine and do not contribute to the photocurrent. Losses 
(a)

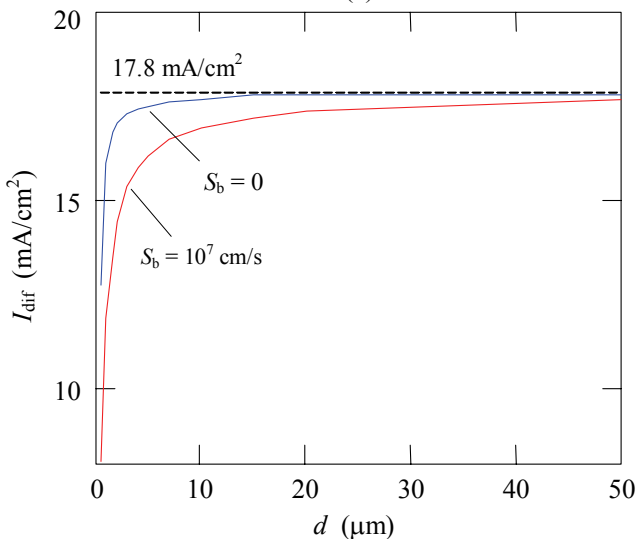

(b)

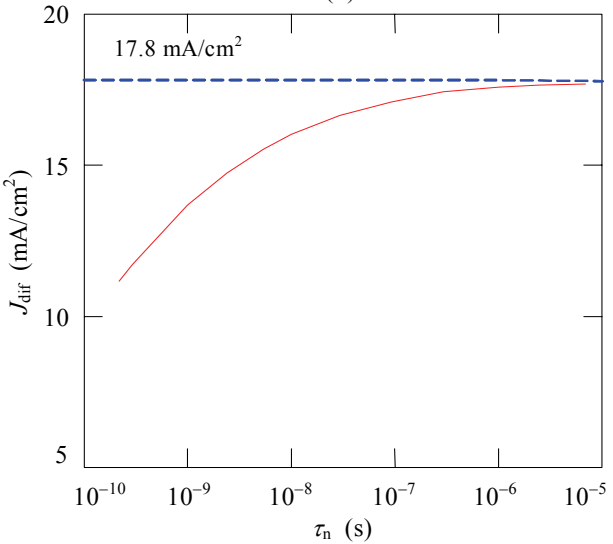

Fig. 6. Diffusion component of the short-circuit current density $J_{\text {dif }}$ as a function of the CdTe layer thickness $d$ calculated at the uncompensated acceptor concentration $N_{\mathrm{a}}-N_{\mathrm{d}}=10^{17} \mathrm{~cm}^{-3}$, the electron lifetime $\tau_{\mathrm{n}}=3 \times 10^{-6} \mathrm{~s}$ and surface recombination velocity $S_{\mathrm{b}}=10^{7} \mathrm{~cm} / \mathrm{s}$ and $S_{\mathrm{b}}=0$ (a) and the dependence of the diffusion current density $J_{\text {dif }}$ on the electron lifetime for the CdTe layer thickness $d=50 \mu \mathrm{m}$ and recombination velocity at the back surface $S_{\mathrm{b}}=10^{7} \mathrm{~cm} / \mathrm{s}(\mathrm{b})$.

caused by the insufficient thickness of the CdTe layer should be considered taking into account this process.

Consider first the spatial distribution of excess electrons in the neutral region governed by the continuity equation with two boundary conditions. At the depletion layer edge, the excess electron density $\Delta n$ can be assumed equal zero (due to electric field in the depletion region), i.e.

$$
\Delta n=0 \text { at } x=W .
$$

At the back surface of the CdTe layer we have surface recombination with a velocity $S_{\mathrm{b}}$ :

$$
S_{\mathrm{b}} \Delta n=-D_{\mathrm{n}} \frac{d \Delta n}{d x} \text { at } x=d,
$$

where $d$ is the thickness of the CdTe layer.

Using these boundary conditions, the exact solution of the continuity equation is (Sze, 1981):

$$
\begin{aligned}
& \Delta n=T(\lambda) N_{\mathrm{o}}(\lambda) \frac{\alpha \tau_{\mathrm{n}}}{\alpha^{2} L_{\mathrm{n}}^{2}-1} \exp [-\alpha W]\left\{\cosh \left(\frac{x-W}{L_{\mathrm{n}}}\right)-\exp [-\alpha(x-W)]-\right. \\
& \left.-\frac{\frac{S_{\mathrm{b}} L_{\mathrm{n}}}{D_{\mathrm{n}}}\left[\cosh \left(\frac{d-W}{L_{\mathrm{n}}}\right)-\exp [-\alpha(d-W)]+\sinh \left(\frac{d-W}{L_{\mathrm{n}}}\right)+\alpha L_{\mathrm{n}} \exp [-\alpha(d-W)]\right.}{\frac{S_{\mathrm{b}} L_{\mathrm{n}}}{D_{\mathrm{n}}} \sinh \left(\frac{x-W}{L_{\mathrm{n}}}\right)+\cosh \left(\frac{d-W}{L_{\mathrm{n}}}\right)} \times \sinh \left(\frac{x-W}{L_{\mathrm{n}}}\right)\right\}
\end{aligned}
$$

where $T(\lambda)$ is the optical transmittance of the glass/TCO/CdS, which takes into account reflection from the front surface and absorption in the TCO and CdS layers, $N_{o}$ is the 
number of incident photons per unit time, area, and bandwidth $\left(\mathrm{cm}^{-2} \mathrm{~s}^{-1} \mathrm{~nm}^{-1}\right), L_{\mathrm{n}}=\left(\tau_{\mathrm{n}} D_{\mathrm{n}}\right)^{1 / 2}$ is the electron diffusion length, $\tau_{\mathrm{n}}$ is the electron lifetime, and $D_{\mathrm{n}}$ is the electron diffusion coefficient related to the electron mobility $\mu_{\mathrm{n}}$ through the Einstein relation: $q D_{\mathrm{n}} / k T=\mu_{\mathrm{n}}$.

Fig. 7 shows the electron distribution calculated by Eq. (15) for different CdTe layer thicknesses. The calculations have been carried out at $\alpha=10^{4} \mathrm{~cm}^{-1}, S_{\mathrm{b}}=7 \times 10^{7} \mathrm{~cm} / \mathrm{s}$, $\mu_{\mathrm{n}}=500 \mathrm{~cm}^{2} /\left(\mathrm{V} \cdot \mathrm{s}\right.$ ) and typical values $\tau_{\mathrm{n}}=10^{-9} \mathrm{~s}$ and $N_{\mathrm{a}}-N_{\mathrm{d}}=10^{16} \mathrm{~cm}^{-3}$ (Sites \& Xiaoxiang, 1996). As it is seen from Fig. 7, even for the CdTe layer thickness of $10 \mu \mathrm{m}$, recombination at back surface leads to a remarkable decrease in the electron concentration. If the layer thickness is reduced, the effect significantly enhances, so that at $d=1-2 \mu \mathrm{m}$, surface recombination "kills" most of the photo-generated electrons. Thus, the photo-generated electrons at $10^{-9} \mathrm{~s}$ are involved in recombination far away from the effective penetration depth of radiation $(\sim 1 \mu \mathrm{m})$. Evidently, the influence of this process enhances as the electron lifetime increases, because the non-equilibrium electrons penetrate deeper into the CdTe layer due to increase of the diffusion length. Calculation using Eq. (15) shows that if the layer thickness is large $(\sim 50 \mu \mathrm{m})$, the non-equilibrium electron concentration reduces 2 times from its maximum value at a distance about $8 \mu \mathrm{m}$ at $\tau_{\mathrm{n}}=10^{-8} \mathrm{~s}, 20 \mu \mathrm{m}$ at $\tau_{\mathrm{n}}=10^{-7} \mathrm{~s}, 32$ $\mu \mathrm{m}$ at $\tau_{\mathrm{n}}=10^{-6} \mathrm{~s}$.

(a)

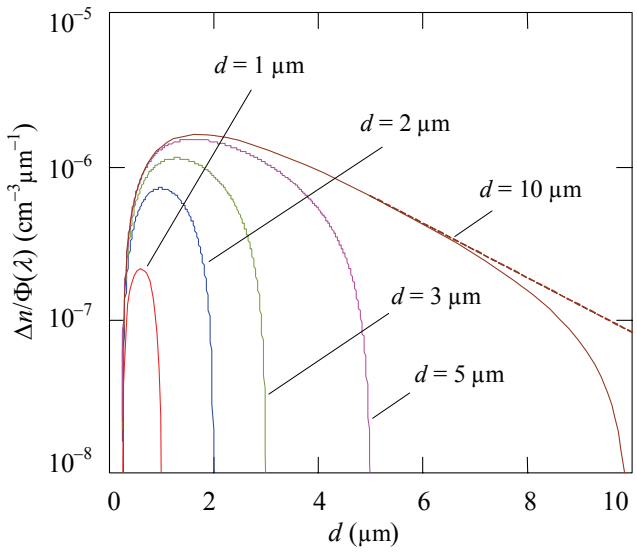

(b)

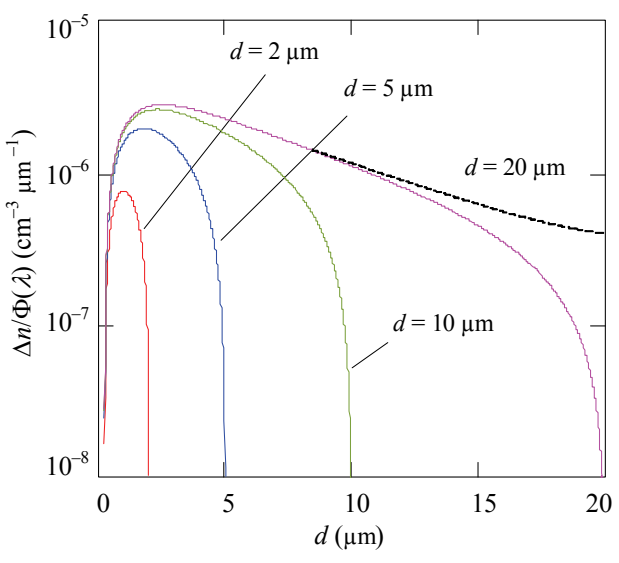

Fig. 7. Electron distribution in the CdTe layer at different its thickness $d$ calculated the electron lifetime $\tau_{\mathrm{n}}=10^{-9} \mathrm{~s}(\mathrm{a})$ and $\tau_{\mathrm{n}}=10^{-8} \mathrm{~s}(\mathrm{~b})$. The dashed lines show the electron distribution for $d=10$ and $20 \mu \mathrm{m}$ if recombination at the back surface is not taken into account.

\subsection{The density of total short-circuit current}

It follows from the above that the processes of the photocurrent formation within the spacecharge region and in the neutral part of the CdTe film are interrelated. Fig. 8 shows the total short-circuit current $J_{s c}$ (the sum of the drift and diffusion components) calculated for different parameters of the CdTe layer, i.e. the uncompensated acceptor concentration, minority carrier lifetime and layer thickness. As the space-charge region is narrow (i.e., $N_{\mathrm{a}}-N_{\mathrm{d}}$ is high), a considerable portion of radiation is absorbed outside the space-charge region. One can see that when the film thickness and electron diffusion length are large enough (the top 
curve in Fig. 8(a) for $d=100 \mu \mathrm{m}, \tau_{\mathrm{n}}>10^{-6} \mathrm{~s}$ ), practically the total charge collection takes place and the density of short-circuit current $J_{\mathrm{sc}}$ reaches its maximum value of $28.7 \mathrm{~mA} / \mathrm{cm}^{2}$ (note, the record experimental value of $J_{s c}$ is $26.7 \mathrm{~mA} / \mathrm{cm}^{2}$ (Holliday et al, 1998) ). However if the

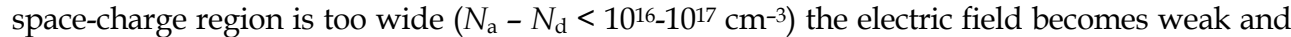
the short-circuit current is reduced due to recombination at the front surface.

For $d=10 \mu \mathrm{m}$, the shape of the curve $J_{\mathrm{sc}}$ versus $N_{\mathrm{a}}-N_{\mathrm{d}}$ is similar to that for $d=100 \mu \mathrm{m}$ but the saturation of the photocurrent density is observed at a smaller value of $J_{\mathrm{sc}}$. A significant lowering of $J_{\mathrm{sc}}$ occurs after further thinning of the CdTe film and, moreover, for $d=5$ and $3 \mu \mathrm{m}$, the short-circuit current even decreases with increasing $N_{\mathrm{a}}-N_{\mathrm{d}}$ due to incomplete charge collection in the neutral part of the CdTe film.

It is interesting to examine quantitatively how the total short-circuit current varies when the electron lifetime is shorter than $10^{-6} \mathrm{~s}$. This is an actual condition because the carrier lifetimes in thin-film CdTe diodes can be as short as $10^{-9}-10^{-10} \mathrm{~s}$ and even smaller (Sites \& Pan, 2007).

(a)

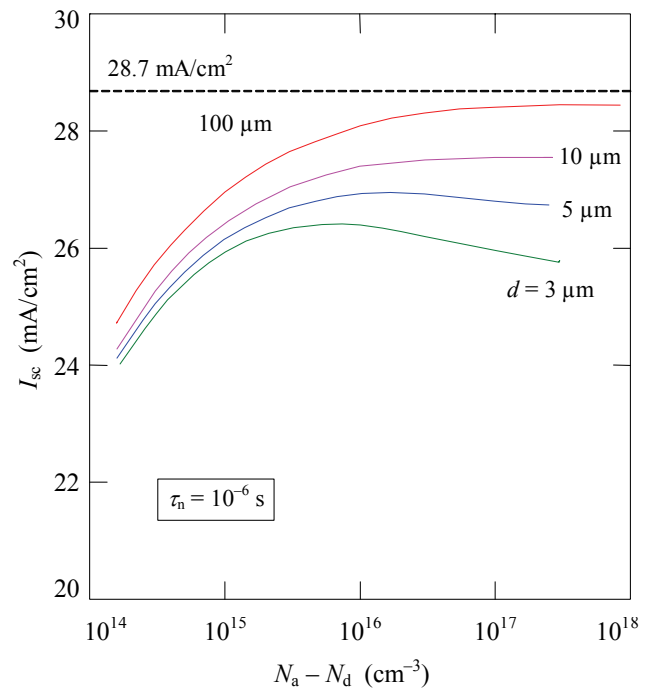

(b)

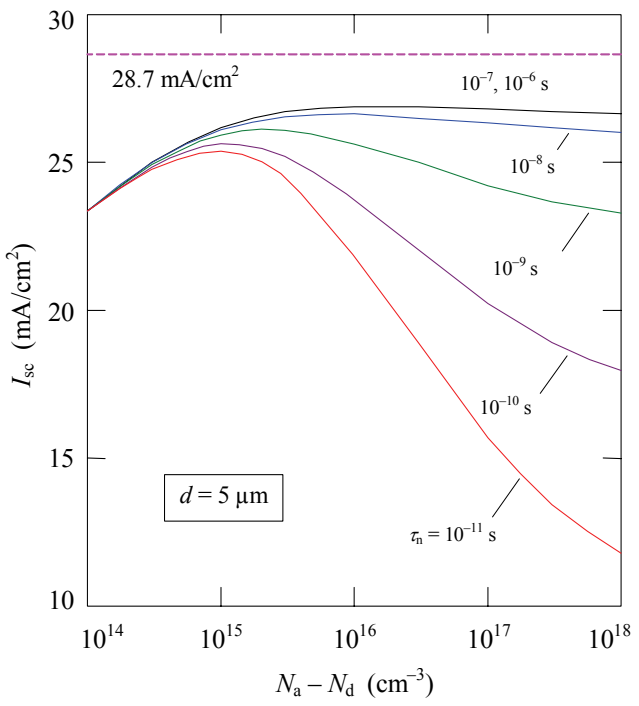

Fig. 8. Total short-circuit current density $J_{\mathrm{sc}}$ of a CdTe-based solar cell as a function of the uncompensated acceptor concentration $N_{\mathrm{a}}-N_{\mathrm{d}}$ calculated at the electron lifetime $\tau_{\mathrm{n}}=10^{-6} \mathrm{~s}$ for different CdTe layer thicknesses $d$ (a) and at the thickness $d=5 \mu \mathrm{m}$ for different $\tau_{\mathrm{n}}(\mathrm{b})$.

Fig. $5(\mathrm{~b})$ shows the calculation results of the total short-circuit current density $J_{\mathrm{sc}}$ versus the concentration of uncompensated acceptors $N_{\mathrm{a}}-N_{\mathrm{d}}$ for different electron lifetimes $\tau_{\mathrm{n}}$. Calculations have been carried out for the CdTe film thickness $d=5 \mu \mathrm{m}$ which is often used in the fabrication of CdTe-based solar cells (Phillips et al., 1996; Bonnet, 2001; Demtsu \& Sites, 2005; Sites \& Pan, 2007). As it can be seen, at $\tau_{\mathrm{n}} \geq 10^{-8} \mathrm{~s}$ the short-circuit current density is $26-27 \mathrm{~mA} / \mathrm{cm}^{2}$ when $N_{\mathrm{a}}-N_{\mathrm{d}}>10^{16} \mathrm{~cm}^{-3}$. For shorter electron lifetime, $J_{\mathrm{sc}}$ peaks in the $N_{\mathrm{a}}-N_{\mathrm{d}}$ range $(1-3) \times 10^{15} \mathrm{~cm}^{-3}$. As $N_{\mathrm{a}}-N_{\mathrm{d}}$ is in excess of this concentration, the short-circuit current decreases since the drift component of the photocurrent reduces. In the range of the uncompensated acceptor concentration $N_{\mathrm{a}}-N_{\mathrm{d}}<(1-3) \times 10^{15} \mathrm{~cm}^{-3}$, the short-circuit current 
density also decreases, but because of recombination at the front surface of the CdTe layer. Anticipating things, it should be noted, that at $N_{\mathrm{a}}-N_{\mathrm{d}}<1015 \mathrm{~cm}^{-3}$, recombination in the space-charge region becomes also significant (see Fig. 9). Thus, in order to reach the shortcircuit current density $25-26 \mathrm{~mA} / \mathrm{cm}^{2}$ when the electron lifetime $\tau_{\mathrm{n}}$ is shorter than $10^{-8} \mathrm{~s}$, the uncompensated acceptor concentration $N_{\mathrm{a}}-N_{\mathrm{d}}$ should be equal to (1-3) $\times 10^{15} \mathrm{~cm}^{-3}$ (rather than $N_{\mathrm{a}}-N_{\mathrm{d}}>10^{16} \mathrm{~cm}^{-3}$ as in the case of $\tau_{\mathrm{n}} \geq 10^{-8} \mathrm{~s}$ ).

\section{Recombination losses in the space-charge region}

In analyzing the photoelectric processes in the CdS/CdTe solar cell we ignored the recombination losses (capture of carriers) in the space-charge region. This assumption is based on the following considerations.

The mean distances that electron and hole travels during their lifetimes along the electric field without recombination or capture by the centers within the semiconductor band gap, i.e. the electron drift length $\lambda_{\mathrm{n}}$ and hole drift length $\lambda_{\mathrm{p}}$, are determined by expressions

$$
\begin{aligned}
& \lambda_{\mathrm{n}}=\mu_{\mathrm{n}} E \tau_{\mathrm{no}}, \\
& \lambda_{\mathrm{p}}=\mu_{\mathrm{p}} E \tau_{\mathrm{po}},
\end{aligned}
$$

where $E$ is the electric-field strength, $\mu_{\mathrm{n}}$ and $\mu_{\mathrm{p}}$ are the electron and hole mobilities, respectively.

In the case of uniform field ( $E=$ const), the charge collection efficiency is expressed by the well-known Hecht equation (Eizen, 1992; Baldazzi et al., 1993):

$$
\eta_{\mathrm{c}}=\frac{\lambda_{\mathrm{n}}}{W}\left[1-\exp \left(-\frac{W-x}{\lambda_{\mathrm{n}}}\right)\right]+\frac{\lambda_{\mathrm{p}}}{W}\left[1-\exp \left(-\frac{x}{\lambda_{\mathrm{p}}}\right)\right] .
$$

In a diode structure, the problem is complicated due to nonuniformity of the electric field in the space-charge region. However, due to the fact that the electric field strength decreases linearly from the surface to the bulk of the semiconductor, the field nonuniformity can be reduced to the substitution of $E$ in Eqs. (16) and (17) by its average values $E_{(0, x)}$ and $E_{(x, W)}$ in the portion $(0, x)$ for electrons and in the portion $(x, W)$ for holes, respectively:

$$
\begin{aligned}
& E_{(x, W)}=\frac{\left(\varphi_{o}-e V\right)}{e W}\left(1-\frac{x}{W}\right), \\
& E_{(0, x)}=\frac{\left(\varphi_{o}-e V\right)}{e W}\left(2-\frac{x}{W}\right) .
\end{aligned}
$$

Thus, with account made for this, the Hecht equation for the space-charge region of $\mathrm{CdS} / \mathrm{CdTe}$ heterostructure takes the form

$$
\eta_{\mathrm{c}}=\frac{\mu_{\mathrm{p}} E_{(x, W)} \tau_{\mathrm{po}}}{W}\left[1-\exp \left(-\frac{W-x}{\mu_{\mathrm{p}} E_{(x, W)} \tau_{\mathrm{po}}}\right)\right]+\frac{\mu_{\mathrm{n}} E_{(0, x)} \tau_{\mathrm{no}}}{W}\left[1-\exp \left(-\frac{x}{\mu_{\mathrm{n}} E_{(0, x)} \tau_{\mathrm{no}}}\right)\right] .
$$


Fig. 9(a) shows the curves of charge-collection efficiency $\eta_{c}(x)$ computed by Eq. (21) for the concentration of uncompensated acceptors $3 \times 10^{16} \mathrm{~cm}^{-3}$ and different carrier lifetimes $\tau=\tau_{\text {no }}$ $=\tau_{\text {po. }}$. It is seen that for the lifetime $10^{-11} \mathrm{~s}$ the effect of losses in the space-charge region is remarkable but for $\tau \geq 10^{-10} \mathrm{~s}$ it is insignificant $\left(\mu_{\mathrm{n}}\right.$ and $\mu_{\mathrm{n}}$ were taken equal to 500 and 60 $\mathrm{cm}^{2} /(\mathrm{V} \cdot \mathrm{s})$, respectively). For larger carrier lifetimes the recombination losses can be neglected at lower values $N_{\mathrm{a}}-N_{\mathrm{d}}$.

Thus, the recombination losses in the space charge-region depend on the concentration of uncompensated acceptors $N_{\mathrm{a}}-N_{\mathrm{d}}$ and carrier lifetime $\tau$ in a complicated manner. It is also seen from Fig. 9(a) that the charge collection efficiency $\eta_{\mathrm{c}}$ is lowest at the interface CdS-CdTe $(x=0)$. An explanation of this lies in the fact that the product $\tau_{\mathrm{no}} \mu_{\mathrm{n}}$ for electrons in CdTe is order of magnitude greater than that for holes. With account made for this, Fig. 9(b) shows the dependences of charge-collection efficiency on $N_{\mathrm{a}}-N_{\mathrm{d}}$ calculated at different carrier lifetimes for the "weakest" place of the space-charge region concerning charge collection of photogenerated carriers, i.e. at the cross section $x=0$. From the results presented in Fig. 9(b), it follows that at the carrier lifetime $\tau \geq 10^{-8} \mathrm{~s}$ the recombination losses can be neglected at the uncompensated acceptor concentration $N_{\mathrm{a}}-N_{\mathrm{d}} \geq 10^{14} \mathrm{~cm}^{-3}$ while at $\tau$

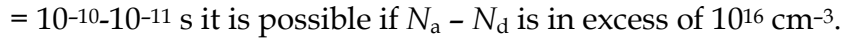

(a)

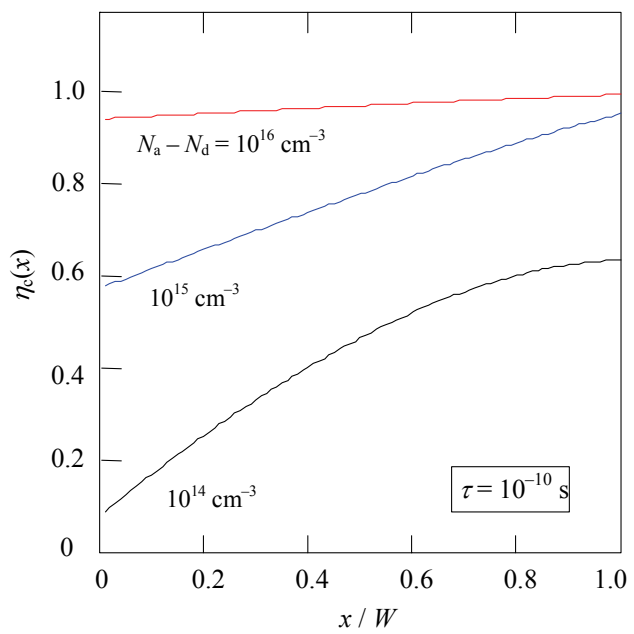

(b)

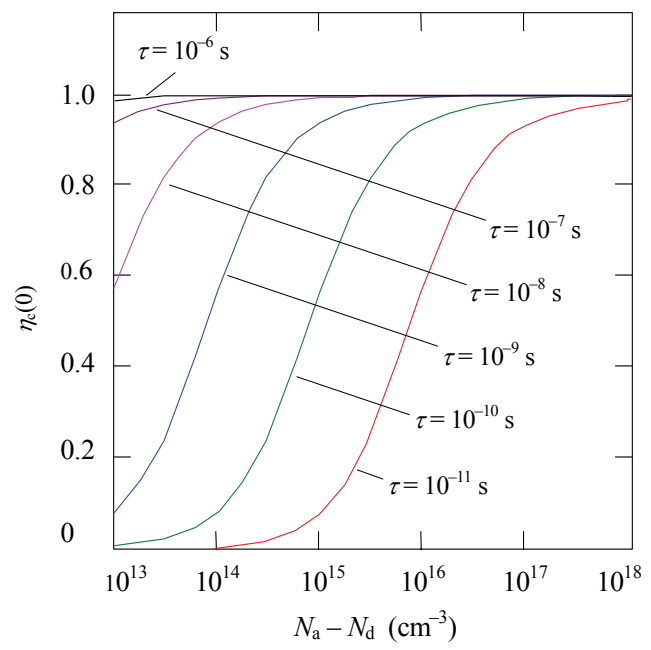

Fig. 9. (a) The coordinate dependences of the charge-collection efficiency $\eta_{c}(x)$ calculated for the uncompensated acceptor concentrations $N_{\mathrm{a}}-N_{\mathrm{d}}=3 \times 10^{16} \mathrm{~cm}^{-3}$ and different carrier lifetimes $\tau$. (b) The charge-collection efficiency $\eta_{\mathrm{c}}$ at the interface CdS-CdTe $(x=0)$ as a function of the uncompensated acceptor concentration $N_{\mathrm{a}}-N_{\mathrm{d}}$ calculated for different carrier lifetimes $\tau$.

\section{Open-circuit voltage, fill factor and efficiency of thin-film CdS/CdTe solar cell}

In this section, we investigate the dependences of the open-circuit voltage, fill factor and efficiency of a CdS/CdTe solar cell on the resistivity of the CdTe absorber layer and carrier 
lifetime with the aim to optimize these parameters and hence to improve the solar cell efficiency. The open-circuit voltage and fill factor are controlled by the magnitude of the forward current. Therefore the $I-V$ characteristic of the device is analyzed which is known to originate primarily by recombination in the space charge region of the CdTe absorber layer.

The $I-V$ characteristic of CdS/CdTe solar cells is most commonly described by the semiempirical formulae which consists the so-called "ideality" factor and is valid for some cases. Contrary to usual practice, in our calculations of the current in a device, we use the recombination-generation Sah-Noyce-Shockley theory developed for p-n junction (Sah et al., 1957) and adopted to CdS/CdTe heterostructure (Kosyachenko et al., 2005) and supplemented with over-barrier diffusion flow of electrons at higher voltages. This theory takes into account the evolution of the $I-V$ characteristic of CdS/CdTe solar cell when the parameters of the CdTe absorber layer vary and, therefore, reflects adequately the real processes in the device.

\section{$5.1 \mathrm{l}-\mathrm{V}$ characteristic of $\mathrm{CdS} / \mathrm{CdTe}$ heterostructure}

The open-circuit voltage, fill factor and efficiency of a solar cell is determined from the $I-V$ characteristic under illumination which can be presented as

$$
J(V)=J_{\mathrm{d}}(V)-J_{\mathrm{ph}},
$$

where $J_{\mathrm{d}}(V)$ is the dark current density and $J_{\mathrm{ph}}$ is the photocurrent density.

The dark current density in the so-called "ideal" solar cell is described by the Shockley equation

$$
J_{\mathrm{d}}(V)=J_{\mathrm{s}}\left[\exp \left(\frac{q V}{k T}\right)-1\right]
$$

where $J_{\mathrm{s}}$ is the saturation current density which is the voltage independent reverse current as $q V$ is higher than few $k T$.

An actual $I-V$ characteristic of CdS/CdTe solar cells differs from Eq. (23). In many cases, a forward current can be described by formula similar to Eq. (23) by introducing an exponent index $q V / A k T$, where $A$ is the "ideality" factor lied in the range 1 to 2 . Sometimes, a close correlation between theory and experiment can be attained by adding the recombination component $I_{\mathrm{o}}[\exp (q V / 2 k T)-1]$ to the dark current in Eq. (23) ( $I_{\mathrm{o}}$ is a new coefficient). Our measurements show, however, that such generalizations of Eq. (23) does not cover the observed variety of $I-V$ characteristics of the CdS/CdTe solar cells. The measured voltage dependences of the forward current are not always exponential and the saturation of the reverse current is never observed. On the other hand, our measurements of $I-V$ characteristics of CdS/CdTe heterostructures and their evolution with the temperature variation are governed by the generation-recombination Sah-Noyce-Shockley theory (Sah al., 1957). According to this theory, the dependence $I \sim \exp (q V / A k T)$ at $n \approx 2$ takes place only in the case where the generation-recombination level is placed near the middle of the band gap. If the level moves away from the midgap the coefficient $A$ becomes close to 1 but only at low forward voltage. If the voltage elevates the $I-V$ characteristic modified in the dependence where $n \approx 2$ and at higher voltages the dependence $I$ on $V$ becomes even weaker (Sah et al., 1957; Kosyachenko et al., 2003). At higher forward currents, it is also necessary to take into account the voltage drop on the series resistance $R_{\mathrm{s}}$ of the bulk part of the CdTe layer by replacing the voltage $V$ in the discussed expressions with $V-I \cdot R_{\mathrm{s}}$. 
The Sah-Noyce-Shockley theory supposes that the generation-recombination rate in the section $x$ of the space-charge region is determined by expression (Sah et al., 1957)

$$
U(x, V)=\frac{n(x, V) p(x, V)-n_{\mathrm{i}}^{2}}{\tau_{\mathrm{po}}\left[n(x, V)+n_{1}\right]+\tau_{\mathrm{no}}\left[p(x, V)+p_{1}\right]},
$$

where $n(x, V)$ and $p(x, V)$ are the carrier concentrations in the conduction and valence bands, $n_{\mathrm{i}}$ is the intrinsic carrier concentration. The values $n_{1}$ and $p_{1}$ are determined by the energy spacing between the top of the valence band and the generation-recombination level $E_{\mathrm{t}}$, i.e. $p_{1}=N_{\mathrm{v}} \exp \left(-E_{\mathrm{t}} / k T\right)$ and $n_{1}=N_{\mathrm{c}} \exp \left[-\left(E_{\mathrm{g}}-E_{\mathrm{t}}\right) / k T\right]$, where $N_{\mathrm{c}}=2\left(m_{\mathrm{n}} k T / 2 \pi \hbar^{2}\right)^{3 / 2}$ and $N_{\mathrm{v}}=2\left(m_{\mathrm{p}} k T / 2 \pi \hbar^{2}\right)^{3 / 2}$ are the effective density of states in the conduction and valence bands, $m_{\mathrm{n}}$ and $m_{\mathrm{p}}$ are the effective masses of electrons and holes, $\tau_{\mathrm{no}}$ and $\tau_{\mathrm{po}}$ are the effective lifetime of electrons and holes in the depletion region, respectively.

The recombination current under forward bias and the generation current under reverse bias are found by integration of $U(x, V)$ throughout the entire depletion layer:

$$
J_{\mathrm{gr}}=q \int_{0}^{W} U(x, V) d x
$$

where the expressions for the electron and hole concentrations have the forms (Kosyachenko et al., 2003):

$$
\begin{gathered}
p(x, V)=N_{\mathrm{c}} \exp \left[-\frac{\Delta \mu+\varphi(x, V)}{k T}\right], \\
n(x, V)=N_{\nu} \exp \left[-\frac{E_{\mathrm{g}}-\Delta \mu-\varphi(x, V)-q V}{k T}\right] .
\end{gathered}
$$

Here $\Delta \mu$ is the energy spacing between the Fermi level and the top of the valence band in the bulk of the CdTe layer, $\varphi(x, V)$ is the potential energy of hole in the space-charge region.

Over-barrier (diffusion) carrier flow in the CdS/CdTe heterostructure is restricted by high barriers for both majority carriers (holes) and minority carriers (electrons) (Fig. 2). For transferring holes from CdTe to CdS, the barrier height in equilibrium $(V=0)$ is somewhat lower than $E_{\mathrm{gCdS}}-\left(\Delta \mu+\Delta \mu_{\mathrm{CdS}}\right)$, where $E_{\mathrm{g} C \mathrm{CdS}}=2.42 \mathrm{eV}$ is the band gap of CdS and $\Delta \mu_{\mathrm{CdS}}$ is the energy spacing between the Fermi level and the bottom of the conduction band of CdS, $\Delta \mu$ is the Fermi level energy in the bulk of CdTe equal to $k \ln \left(N_{\mathrm{v}} / p\right), p$ is the hole concentration which depends on the resistivity of the material. An energy barrier impeding electron transfer from CdS to CdTe is also high but is equal to $E_{\mathrm{g}} \mathrm{CdTe}-\left(\Delta \mu+\Delta \mu_{\mathrm{CdS}}\right)$ at $V=0$. Owing to high barriers for electrons and holes, under low and moderate forward voltages the dominant charge transport mechanism is recombination in the space-charge region. However, as $q V$ nears $\varphi_{0}$, the over-barrier currents become comparable and even higher than the recombination current due to much stronger dependence on $V$. Since in CdS/CdTe junction the barrier for holes is considerably higher than that for electrons, the electron component dominates the over-barrier current. Obviously, the electron flow current is analogous to that occurring in a p-n junction and one can write for the over-barrier current density (Sze, 1981): 


$$
J_{\mathrm{n}}=q \frac{n_{\mathrm{p}} L_{\mathrm{n}}}{\tau_{\mathrm{n}}}\left[\exp \left(\frac{q V}{k T}\right)-1\right],
$$

where $n_{\mathrm{p}}=N_{\mathrm{c}} \exp \left[-\left(E_{\mathrm{g}}-\Delta \mu\right) / k T\right]$ is the concentration of electrons in the p-CdTe layer, $\tau_{\mathrm{n}}$ and $L_{\mathrm{n}}=\left(\tau_{\mathrm{n}} D_{\mathrm{n}}\right)^{1 / 2}$ are the electron lifetime and diffusion length, respectively $\left(D_{\mathrm{n}}\right.$ is the diffusion coefficient of electrons).

Thus, according to the above discussion, the dark current density in CdS/CdTe heterostructure $J_{\mathrm{d}}(V)$ is the sum of the generation-recombination and diffusion components:

$$
J_{\mathrm{d}}(V)=J_{g \mathrm{r}}(V)+J_{\mathrm{n}}(V) \text {. }
$$

\subsection{Comparison with the experimental data}

The current-voltage characteristics of CdS/CdTe solar cells depend first of all on the resistivity of the CdTe absorber layer due to the voltage drop across the series resistance of the bulk part of the CdTe film $R_{\mathrm{s}}$ (Fig. 10(a)). The value of $R_{s}$ can be found from the voltage dependence of the differential resistance $R_{\text {dif }}$ of a diode structure under forward bias. Fig. 10 shows the results of measurements taken for two "extreme" cases: the samples No 1 and 2 are examples of the CdS/CdTe solar cells with low resistivity $(20 \Omega \cdot \mathrm{cm})$ and high resistivity of the CdTe film $\left(4 \times 10^{7} \Omega \cdot \mathrm{cm}\right)$, respectively. One can see that, in the region of low voltage, the $R_{\text {dif }}$ values decrease with $V$ by a few orders of magnitude. However, at $V>0.5-0.6 \mathrm{~V}$ for sample No 1 and $V>0.8-0.9 \mathrm{~V}$ for sample No $2, R_{\text {dif }}$ reaches saturation values which are obviously the series resistances of the bulk region of the film $R_{\mathrm{s}}$.

(a)

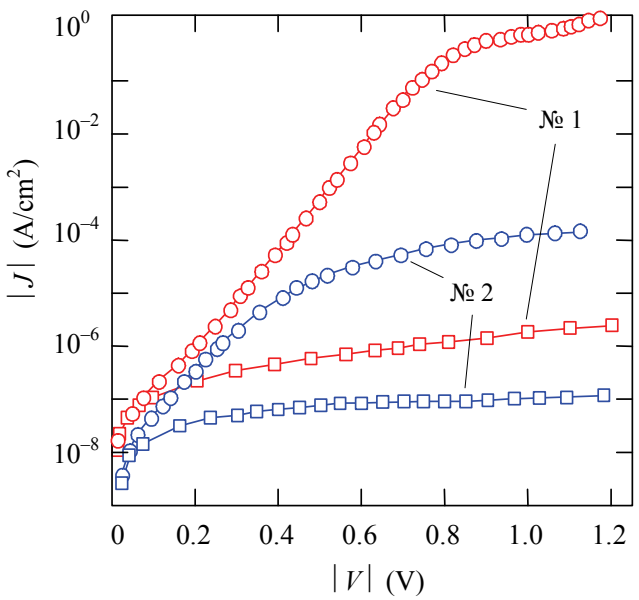

(b)

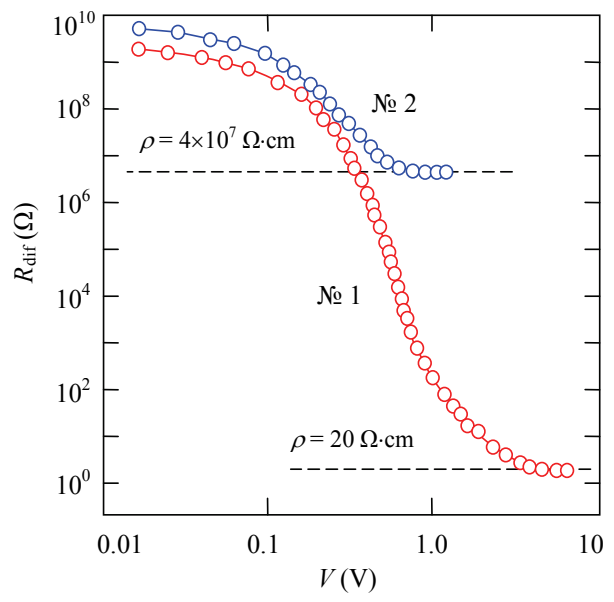

Fig. 10. $I-V$ characteristics (a) and dependences of differential resistances $R_{\text {dif }}$ on forward voltage (b) for two solar cells with different resistivities of CdTe layers: 20 and $4 \times 10^{7} \Omega \cdot \mathrm{cm}$ $(300 \mathrm{~K})$.

Because the value of $R_{\mathrm{s}}$ for a sample No 1 is low, the presence of $R_{\mathrm{s}}$ does not affect the shape of the diode $I-V$ characteristic. In contrast, the resistivity of the CdTe film for a sample No 2 is $\sim 6$ orders higher, therefore at moderate forward currents $\left(J>10^{-6} \mathrm{~A} / \mathrm{cm}^{2}\right)$, the 
experimental points deviate from the exponential dependence which is strictly obeyed for sample No 1 over 6 orders of magnitude.

The experimental results presented in Fig. 11 reflect the common feature of the $I-V$ characteristic of a thin-film CdS/CdTe heterostructure (sample No 1). The results obtained for this sample allow interpreting them without complications caused by the presence of the series resistance $R_{\mathrm{s}}$. Nevertheless, in this case too, the forward $I-V$ characteristic reveals some features which are especially pronounced. As one can see, under forward bias, there is an extended portion of the curve $(0.1<V<0.8 \mathrm{~V})$ where the dependence $I \sim \exp (q V / A k T)$ holds for $A=1.92$. At higher voltages, the deviation from the exponential dependence toward lower currents is observed. It should be emphasized that this deviation is not caused by the voltage drop across the series resistance of the neutral part of the CdTe absorber layer $R_{\mathrm{s}}$ (which is too low in this case). If the voltage elevates still further $(>1 \mathrm{~V})$, a much steeper increase of forward current is observed.

Analysis shows that all of varieties of the thin-film $I-V$ characteristics are explained in the frame of mechanism involving the generation-recombination in the space-charge region in a wide range of moderate voltages completed by the over-barrier diffusion current at higher voltage.

The results of comparison between the measured $I-V$ characteristic of the thin-film CdS/CdTe heterostructure (circles) and that calculated using Eqs. (25), (28) and (29) (lines) are shown in Fig. 11.
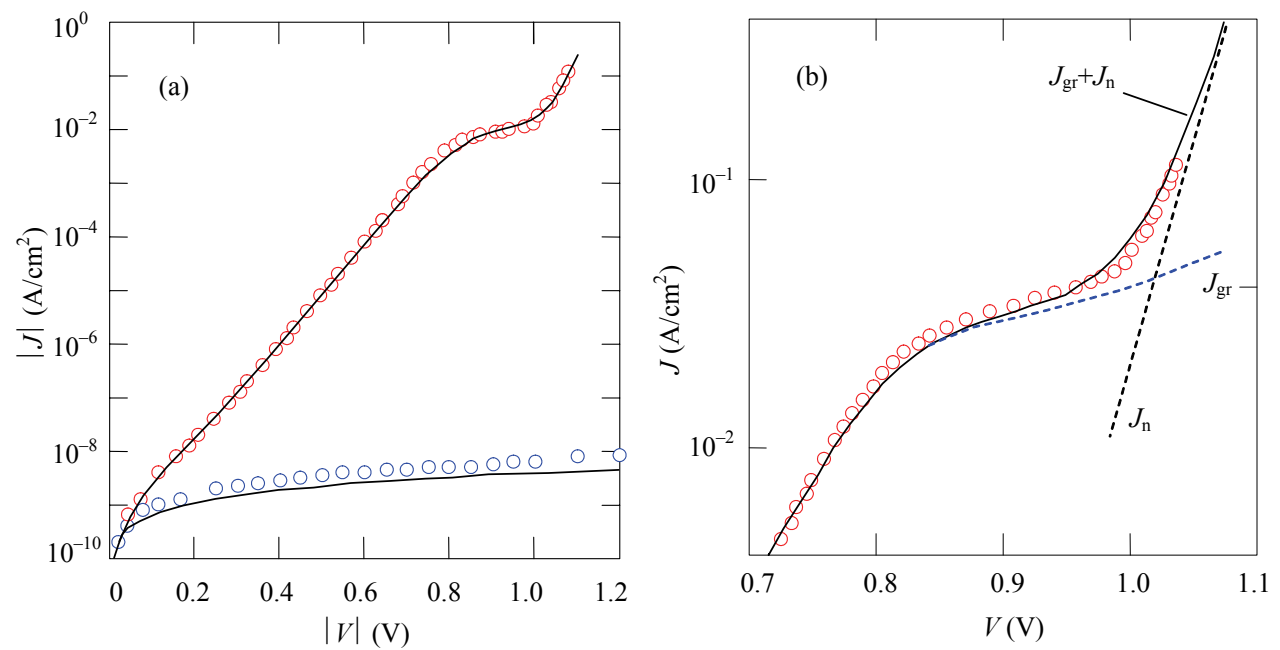

Fig. 11. (a) $I-V$ characteristic of thin-film CdS/CdTe heterostructure. The circles and solid lines show the experimental and calculated results, respectively. (b) Comparison of the calculated and measured dependences in the range of high forward currents $\left(J_{\mathrm{gr}}\right.$ and $J_{\mathrm{n}}$ are the recombination and diffusion components, respectively).

To agree the calculated results with experiment, the effective lifetimes of electrons and holes in the space-charge region were taken $\tau_{\mathrm{no}}=\tau_{\mathrm{po}}=\tau=1.2 \times 10^{-10} \mathrm{~s}(\tau$ determines the value of current but does not affect the shape of curve). The ionization energy $E_{\mathrm{t}}$ was accepted to be $0.73 \mathrm{eV}$ as the most effective recombination center (the value $E_{\mathrm{t}}$ determines the rectifying 
coefficient of the diode structure), the barrier height $\varphi_{\mathrm{o}}$ and the uncompensated acceptor concentration $N_{\mathrm{a}}-N_{\mathrm{d}}$ were taken $1.13 \mathrm{eV}$ and $10^{17} \mathrm{~cm}^{-3}$, respectively. One can see that the $I-V$ characteristic calculated in accordance with the above theory (lines) are in good agreement with experiment both for the forward and reverse connection (circles).

Attention is drawn to the fact that the effective carrier lifetime in the space charge region $\tau=\left(\tau_{n 0} \tau_{p 0}\right)^{1 / 2}$ was taken equal to $1.5 \times 10^{-8} \mathrm{~s}$ whereas the electron lifetime $\tau_{\mathrm{n}}$ in the crystals is in the range of $10^{-7} \mathrm{~s}$ or longer (Acrorad Co, Ltd., 2009). Such a significant difference between $\tau$ and $\tau_{\mathrm{n}}$ appears reasonable since $\tau_{\mathrm{n}}$ is proportional to $1 / N_{\mathrm{t}} f$, where $N_{\mathrm{t}}$ is the concentration of recombination centers and $f$ is the probability that a center is empty. Both of the values $\tau_{\mathrm{n} 0}$ and $\tau_{\mathrm{p} 0}$ in the Sah-Noyce-Shockley theory are proportional to $1 / N_{\mathrm{t}}$. At the same time, since the probability $f$ in the bulk part of the diode structure can be much less than unity, the electron lifetime $\tau_{\mathrm{n}}$ can be far in excess of the effective carrier lifetime $\tau$ in the space-charge region.

\subsection{Dependences of open-circuit voltage, fill factor and efficiency on the parameters of thin-film CdS/CdTe solar cell}

The open-circuit voltage $V_{\mathrm{oc}}$, fill factor $F F$ and efficiency $\eta$ of a solar cell is determined from the $I-V$ characteristic under illumination which can be presented as

$$
J(V)=J_{\mathrm{d}}(V)-J_{\mathrm{ph}},
$$

where $J_{\mathrm{d}}(V)$ and $J_{\mathrm{ph}}$ are the dark current and photocurrent densities, respectively.

Calculations carried out for the case of a film thickness $d=5 \mu \mathrm{m}$ which is often used in the fabrication of CdTe-based solar cells and a typical carrier lifetime of $10^{-9}-10^{-10} \mathrm{~s}$ (Sites et al., 2007 ) in thin-film CdTe/CdS solar cells show that the maximum value of $J_{\mathrm{sc}} \approx 25-26 \mathrm{~mA} / \mathrm{cm}^{2}$ (Fig. 8(b)) is obtained when the concentration of noncompensated acceptors is $N_{\mathrm{a}}-N_{\mathrm{d}}=$ $10^{15}-10^{16} \mathrm{~cm}^{-3}$. Therefore, in the following calculations a photocurrent density $J_{\mathrm{sc}} \approx 26$ $\mathrm{mA} / \mathrm{cm}^{2}$ will be used.

In Fig. 12(a) the calculated $I-V$ characteristics of the CdS/CdTe heterojunction under illumination are shown. The curves have been calculated by Eq. (30) using Eqs. (25), (28), (29) for $\tau=\tau_{\mathrm{no}}=\tau_{\mathrm{po}}=10^{-9} \mathrm{~s}, N_{\mathrm{a}}-N_{\mathrm{d}}=10^{16} \mathrm{~cm}^{-3}$ and various resistivities of the p-CdTe layer. As is seen, an increase in the resistivity $\rho$ of the CdTe layer leads to decreasing the opencircuit voltage $V_{\mathrm{oc}}$. As $\rho$ varies, $\Delta \mu$ also varies affecting the value of the recombination current, and especially the over-barrier current. The shape of the curves also changes affecting the fill factor $F F$ which can be found as the ratio of the maximum electrical power to the product $J_{\mathrm{sc}} V_{\mathrm{oc}}$ (Fig. 12(a)). Evidently, the carrier lifetime $\tau_{\mathrm{n}}$ also influences the $I-V$ characteristic of the heterojunction under illumination. In what follows the dependences of these characteristics on $\rho$ and $\tau$ are analyzed.

The dependences of open-circuit voltage, fill factor and efficiency on the carrier lifetime calculated at different resistivities of the CdTe absorber layer are shown in Fig. 13. As is seen, $V_{\mathrm{oc}}$ considerably increases with lowering $\rho$ and increasing $\tau$. In the most commonly

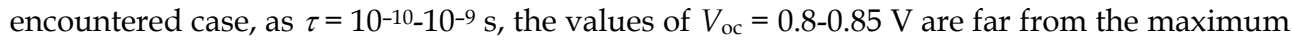
possible values of 1.15-1.2 V, which are reached on the curve for $\rho=0.1 \Omega \cdot \mathrm{cm}$ and $\tau>10^{-8}$. A remarkable increase of $V_{\text {oc }}$ is observed when $\rho$ decreases from $10^{3}$ to $0.1 \Omega \cdot \mathrm{cm}$. 
(a)

$V(\mathrm{~V})$

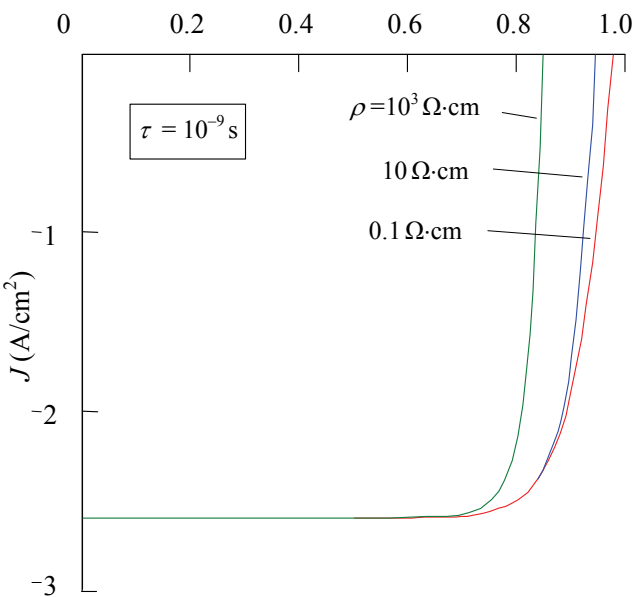

(b)

$V(\mathrm{~V})$

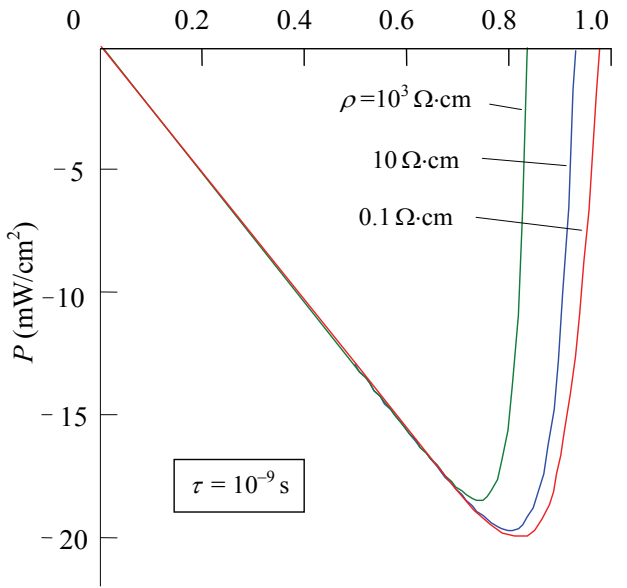

Fig. 12. I-V characteristics (a) and voltage dependence of the output power (b) of CdS/CdTe heterojunction under AM1.5 solar irradiation calculated for $J_{\mathrm{sc}}=26 \mathrm{~mA} / \mathrm{cm}^{2}, \tau=10^{-9} \mathrm{~s}$ and different resistivities $\rho$ of the CdTe absorber layer.

Fig. 13(b) illustrates the dependence of the fill factor $F F=P_{\max } /\left(J_{\mathrm{sc}} \cdot V_{\mathrm{oc}}\right)$ on the parameters of the CdS/CdTe heterostructure within the same range of $\rho$ and $\tau\left(P_{\max }\right.$ is the maximal output power found from the illuminated $I-V$ characteristic). As it is seen, the fill factor increases from $0.81-0.82$ to $0.88-0.90$ with the increase of the carrier lifetime from $10^{-11}$ to $10^{-7} \mathrm{~s}$. The non-monotonic dependence of $F F$ on $\tau$ for $\rho=0.1 \Omega \cdot \mathrm{cm}$ is caused by the features of the $I-V$ characteristics of the CdS/CdTe heterostructures, namely, the deviation of the $I-V$ dependence from exponential law when the resistivity of CdTe layer is low (see Fig. 11, $V>0.8 \mathrm{~V})$.

Finally, the dependences of the efficiency $\eta=P_{\text {out }} / P_{\text {irr }}$ on the carrier lifetime $\tau_{\mathrm{n}}$ calculated for various resistivities of the CdTe absorber layer are shown in Fig. 13(c), where $P_{\text {irr }}$ is the AM 1.5 solar radiation power over the entire spectral range which is equal to $100 \mathrm{~mW} / \mathrm{cm}^{2}$ (Standard IOS, 1992). As it is seen, the value of $\eta$ remarkably increases from $15-16 \%$ to $21-$ $27.5 \%$ when $\tau$ and $\rho$ changes within the indicated limits. For $\tau=10^{-10}-10^{-9} \mathrm{~s}$, the efficiency lies near $17-19 \%$ and the enhancement of $\eta$ by lowering the resistivity of CdTe layer is $0.5-$ 1.5\% (the shaded area in Fig. 13(c)).

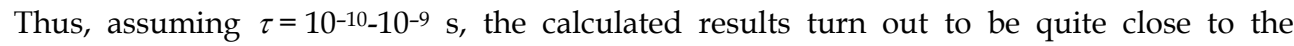
experimental efficiencies of the best samples of thin-film CdS/CdTe solar cells (16-17\%).

The conclusion followed from the results presented in Fig. 13(c) is that in the case of a CdS/CdTe solar cell with CdTe thickness $5 \mu \mathrm{m}$, enhancement of the efficiency from $16-17 \%$ to $27-28 \%$ is possible if the carrier lifetime increases to $\tau \geq 10^{-6} \mathrm{~s}$ and the resistivity of CdTe reduces to $\rho \approx 0.1 \Omega \cdot \mathrm{cm}$. Approaching the theoretical limit $\eta=27-28 \%$ requires also an increase in the short-circuit current density. As it is follows from section 3.3, the latter is possible for the thickness of the CdTe absorber layer of 20-30 $\mu \mathrm{m}$ and more. 

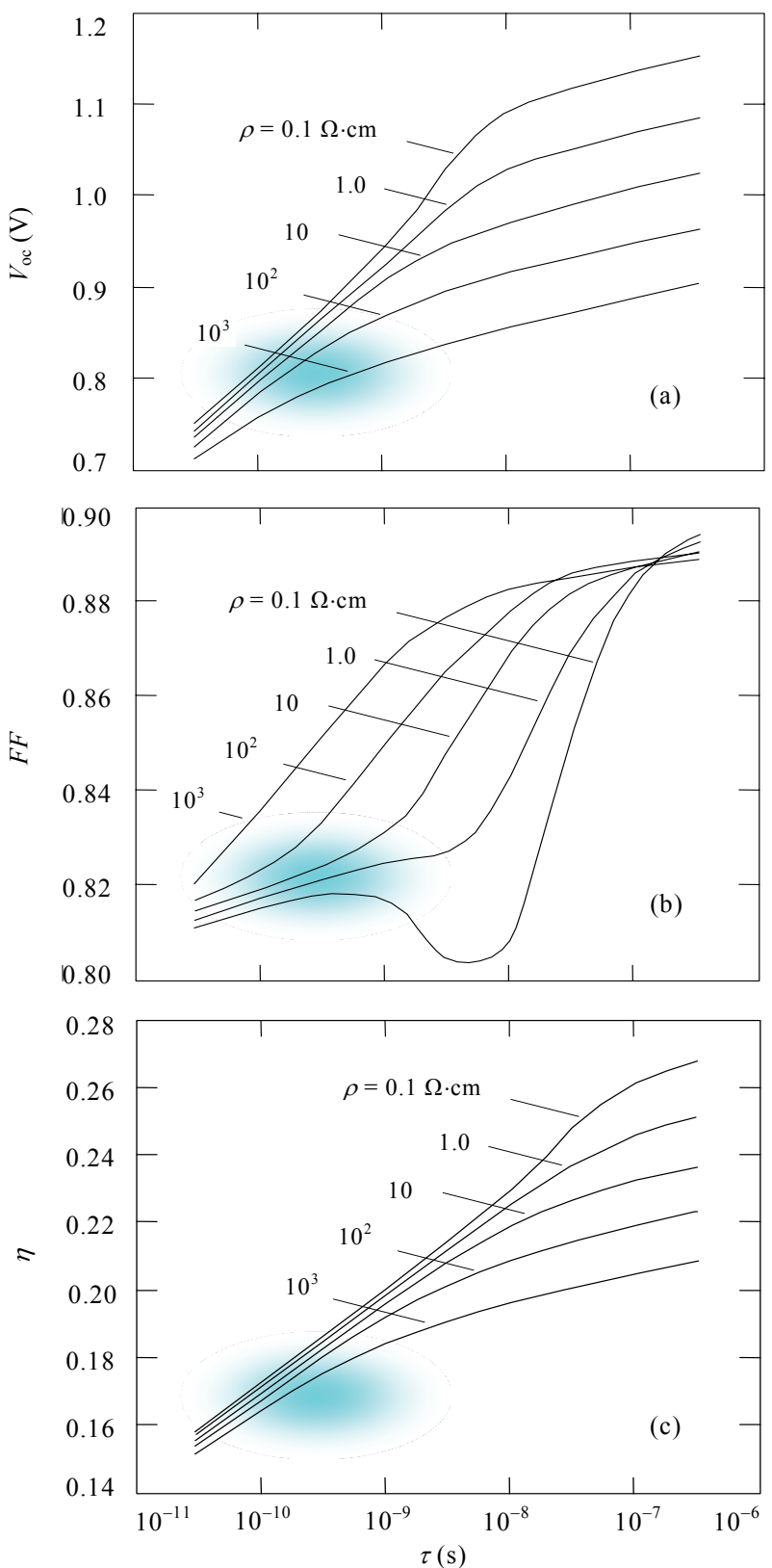

Fig. 13. Dependences of the open-circuit voltage $V_{\text {oc }}(\mathrm{a})$, fill factor $F F(\mathrm{~b})$ and efficiency $\eta$ (c) of CdS/CdTe heterojunction on the carrier lifetime $\tau$ calculated by Eq. (30) using Eqs. (24)(29) for various resistivities $\rho$ of the CdTe layer. The experimental results achieved for the best samples of thin-film CdS/CdTe solar cells are shown by shading. 


\section{Conclusion}

The findings of this paper give further insight into the problems and ascertain some requirements imposed on the CdTe absorber layer parameters in a CdTe/CdS solar cell, which in our opinion could be taken into account in the technology of fabrication of solar cells.

The model taking into account the drift and diffusion photocurrent components with regard to recombination losses in the space-charge region, at the CdS-CdTe interface and the back surface of the CdTe layer allows us to obtain a good agreement with the measured quantum efficiency spectra by varying the uncompensated impurity concentration, carrier lifetime and surface recombination velocity. Calculations of short-circuit current using the obtained efficiency spectra show that the losses caused by recombination at the CdTe-CdS interface are insignificant if the uncompensated acceptor concentration $N_{\mathrm{a}}-N_{\mathrm{d}}$ in CdTe is in excess of $10^{16} \mathrm{~cm}^{-3}$. At $N_{\mathrm{a}}-N_{\mathrm{d}} \approx 10^{16} \mathrm{~cm}^{-3}$ and the thickness of the absorbing CdTe layer equal to around $5 \mu \mathrm{m}$, the short-circuit current density of $25-26 \mathrm{~mA} / \mathrm{cm}^{2}$ can be attained. As soon as $N_{\mathrm{a}}-N_{\mathrm{d}}$ deviates downward or upward from this value, the short-circuit current density decreases significantly due to recombination losses or reduction of the photocurrent diffusion component, respectively. Under this condition, recombination losses in the spacecharge region can be also neglected, but only when the carrier lifetime is equal or greater than $10^{-10} \mathrm{~s}$.

At $N_{\mathrm{a}}-N_{\mathrm{d}} \geq 10^{16} \mathrm{~cm}^{-3}$, when only a part of charge carriers is generated in the neutral part of the p-CdTe layer, total charge collection can be achieved if the electron lifetime is equal to several microseconds. In this case the CdTe layer thickness $d$ should be greater than that usually used in the fabrication of CdTe/CdS solar cells $(2-10 \mu \mathrm{m})$. However, in a common case where the minority-carrier (electron) lifetime in the absorbing CdTe layer amounts to $10^{-10}-10^{-9} \mathrm{~s}$, the optimum layers thickness $d$ is equal to $3-4 \mu \mathrm{m}$, i.e., the calculations support the choice of $d$ made by the manufacturers mainly on an empirical basis. Attempts to reduce the thickness of the CdTe layer to 1-1.5 $\mu \mathrm{m}$ with the aim of material saving appear to be unwarranted, since this leads to a considerable reduction of the short-circuit's current density $J_{\mathrm{sc}}$ and, ultimately, to a decrease in the solar-cell efficiency. If it will be possible to improve the quality of the absorbing layer and, thus, to raise the electron lifetime at least to $10^{-8} \mathrm{~s}$, the value of $J_{\mathrm{sc}}$ can be increased by $1-1.5 \mathrm{~mA} / \mathrm{cm}^{2}$.

The Sah-Noyce-Shockley theory of generation-recombination in the space-charge region supplemented with over-barrier diffusion flow of electrons provides a quantitative explanation for all variety of the observed $I-V$ characteristics of thin-film CdS/CdTe heterostructure. The open circuit voltage $V_{\mathrm{oc}}$ significantly increases with decreasing the resistivity $\rho$ of the CdTe layer and increasing the effective carrier lifetime $\tau$ in the space charge region. At $\tau=10^{-10-10^{-9}} \mathrm{~s}$, the value of $V_{\text {oc }}$ is considerably lower than its maximum possible value for $\rho \approx 0.1 \Omega \cdot \mathrm{cm}$ and $\tau>10^{-8} \mathrm{~s}$ and the calculated efficiency of a CdS/CdTe solar cell with a CdTe layer thickness of $5 \mu \mathrm{m}$ lies in the range 17-19\%. An increase in the efficiency and an approaching its theoretical limit (28-30\%) is possible in the case when the electron lifetime $\tau_{\mathrm{n}} \geq 10^{-6} \mathrm{~s}$ and the thickness of CdTe absorber layer is 20-30 $\mu \mathrm{m}$ or more. The question of whether an increase in the CdTe layer's thickness is reasonable under the conditions of mass production of solar modules can be answered after an analysis of economic factors. 


\section{Acknowledgements}

I thank X. Mathew, Centro de Investigacion en Energia-UNAM, Mexico, for the CdS/CdTe thin-film heterostructures for measurements, V.M. Sklyarchuk for sample preparation to study, V.V. Motushchuk and E.V. Grushko for measurements carried out, and all participants of the investigation for helpful discussion. The study was supported by the State Foundation for Fundamental Investigations (Ministry of Education and Science, Ukraine) within the Agreement $\Phi 14 / 259-2007$.

\section{References}

Acrorad Co, Ltd., 13-23 Suzaki, Gushikawa, Okinawa 904-2234, Japan. Available: http://www.acrorad.jp/us/cdte.html.

Aramoto T., Kumazawa S., Higuchi H., Arita T., Shibutani S., Nishio T., Nakajima J., Tsuji M., Hanafusa A., Hibino T., Omura K., Ohyama H. \&, Murozono M., (1997). 16.0\% Efficient Thin-Film CdS/CdTe Solar Cells. J. Appl. Phys. 36, 6304-6305.

Baldazzi G., Bollini D., Casali F., Chirco P., Donati A., Dusi W., Landini G., Rossi M. \& Stephen J. B., (1993). Timing response of CdTe detectors, Nucl. Instr. and Meth. A326 319-324.

Birkmire, R.W. \& Eser, E. (1997). Polycrystalline thin film solar cells: Present status and future potential, Annu. Rev. Mater. Sc. 27, 625.

Britt, J. \& Ferekides, C., (1993), Thin-film CdS/CdTe solar cell with $15.8 \%$ efficiency. Appl. Phys. Lett. 62, 2851-2853.

Bonnet, D. (2001). Cadmium telluride solar cells. In: Clean Electricity from Photovoltaic. Ed. by M.D. Archer, R. Hill. Imperial College Press, pp. 245-276.

Bonnet, D. (2003). CdTe thin-film PV modules, In: Practical Handbook of Photovoltaic: Fundamentals and Applications. Ed. by T. Makkvart and L. Castaner. Elseivier, Oxford.

Compaan A.D., Sites J.R., Birkmire R.W., Ferekides C.S. and Fahrenbruch A.L. (1999). Critical Issues and Research Needs for CdTe-Based Solar Cells, Proc. 195th Meeting of the Electrochemical Society), PV99-11, Seattle, WA, pp. 241-249.

Demtsu S.H. \& Sites J.R., (2005). Quantification of losses in thin-film CdS/CdTe solar cells, Proc. 31rd IEEE Photovoltaic Specialists Conf. pp. 3-7, Florida, Jan. 347-350.

Desnica, U.V., Desnica-Frankovic I.D., Magerle R., Burchard A. \& Deicher M.. (1999). Experimental evidence of the self-compensation mechanism in CdS, J. Crystal Growth, 197, 612-615.

Eizen Y. (1992). Current state-of-the-art applications utilizing CdTe derectors, Nucl. Instr. and Meth. A322, 596-603.

Ferekides, C.S., Balasubramanian, U., Mamazza, R., Viswanathan, V., Zhao, H. \& Morel, D.L. (2004) CdTe thin-film solar cells: device and technology issues, Solar Energy 77, 823-830.

Fritsche, J., Kraft, D., Thissen, A., Mayer, Th., Klein \& A., Jaegermann W. (2001). Interface engineering of chalcogenide semiconductors in thin film solar cells: CdTe as an example, Mat. Res. Soc. Symp. Proc. , 668, 601-611.

Gartner W.W., (1959). Depletion-layer photoeffects in semiconductors, Phys. Rev. 116, 84-87. 
Goetzberger, A. , Hebling, C. \& Schock, H.-W. (2003). Photovoltaic materials, history, status and outlook, Materials Science and Engineering R40, 1-46.

Grasso, C., Ernst, K., R. Könenkamp, Lux-Steiner, M.C. \& Burgelman, M. (2001). Photoelectrical Characterisation and Modelling of the Eta-Solar Cell. Proc. 17th European Photovoltaic Solar Energy Conference, vol. 1. pp. 211-214, Munich, Germany, 22-26 October.

Hanafusa, A., Aramoto, T., Tsuji, M., Yamamoto, T., Nishio, T., Veluchamy, P., Higuchi, H., Kumasawa, S., Shibutani, S., Nakajima, J., Arita T., Ohyama, H., Hibino T., Omura \& K. (2001). Highly efficient large area $(10.5 \%, 1376 \mathrm{~cm} 2)$ thin-film CdS/CdTe solar cell, Solar Energy Materials \& Solar Cells. 67, 21-29.

Holliday D. P., Eggleston J. M. and Durose K., (1998). A photoluminescence study of polycrystalline thin-film CdTe/CdS solar cells. J. Cryst. Growth. 186, 54-549.

Kosyachenko, L.A., Sklyarchuk, V.M. , Sklyarchuk, Ye.F. \& Ulyanitsky, K.S. (1999). Surfacebarrier p-CdTe-based photodiodes, Semicond. Sci. Technol., 14, 373-377.

Kosyachenko L.A., Rarenko I.M., Zakharuk Z.I., Sklyarchuk V.M., Sklyarchuk Ye.F., Solonchuk I.V., Kabanova I.S. \& Maslyanchuk E.L. (2003). Electrical properties of CdZnTe surface-barrier diodes. Semiconductors. 37, 238-242.

Kosyachenko L.A., Mathew X., Motushchuk V.V. \& Sklyarchuk V.M. (2005). The generationrecombination mechanism of charge transport in a thin-film CdS/CdTe heterojunction, Semiconductors, 39, 539-542.

Kosyachenko, L.A. (2006). Problems of Efficiency of Photoelectric Conversion in Thin-Film CdS/CdTe Solar Cells, Semiconductors. 40, 710-727.

Lavagna, M., Pique, J.P. \& Marfaing, Y. (1977). Theoretical analysis of the quantum photoelectric yield in Schottky diodes, Solid State Electronics, 20, 235-240.

Mathew, X., Kosyachenko, L.A., Motushchuk, V.V. \& Sklyarchuk. O.F. (2007). Requirements imposed on the electrical properties of the absorbed layer in CdTe-based solar cells. J. Materials Science: Materials in Electronics. 18, 1021-1028.

McCandless, B.E., Hegedus, S.S., Birkmire, R.W. \& Cunningham, D. (2003). Correlation of surface phases with electrical behavior in thin-film CdTe. devices. Thin Solid Films 431-432, 249-256.

Meyers, P.V. \& Albright, S.P. (2000). Photovoltaic materials, history, status and outlook. Prog. Photovolt.: Res. Appl. 8, 161- 168.

Phillips J.I., Brikmire R.W., McCandless B.E., Mayers P.V. \& Shaparman W.N., (1996). Polycrystalline heterojunction solar cells: a device perspective. Phys. Stat. Sol. (b) 31, 31-39.

Reference solar spectral irradiance at the ground at different receiving conditions. Standard of International Organization for Standardization ISO 9845-1:1992.

Romeo, N., Bosio, Canevari, A. V. \& Podesta A., (2004). Recent progress on CdTe/CdS thin film solar cells, Solar Energy , 77, 795-801.

Sah C., Noyce R. \& Shockley W. (1957). Carrier generalization recombination in p-n junctions and p-n junction characteristics, Proc. IRE. 45, 1228-1242.

Sites, J.R. \& Xiaoxiang Liu, (1996). Recent efficiency gains for CdTe and $\mathrm{CuIn}_{1-\mathrm{x}} \mathrm{Ga}_{\mathrm{x}} \mathrm{Se} 2$ solar cells: What has changed? Solar Energy Materials \& Solar cells. 41/42 373-379. 
Sites J.R. \& Pan J., (2007). Strategies to increase CdTe solar-cell voltage. Thin Solid Films, 515, 6099-6102.

Surek, T. (2005). Crystal growth and materials research in photovoltaics: progress and challenges, Journal of Crystal Growth. 275, 292-304.

Sze, S. (1981). Physics of Semiconductor Devices, 2nd ed. Wiley, New York.

Toshifumi, T., Adachi, S., Nakanishi, H. \& Ohtsuka M. (993). K. Optical constants of Zn1-xCdxTe Ternary alloys: Experiment and Modeling. Jpn. Appl. Phys. 32, 34963501.

Wu, X., Keane, J.C., Dhere, R.G., Dehart, C., Albin, D.S., Duda, A., Gessert, T.A., Asher, S., Levi, D.H. \& Sheldon, P. (2001). 16.5\%-efficient CdS/CdTe polycrystalline thin-film solar cell, In: Proceedings of the 17th European Photovoltaic Solar Energy Conference, Munich, Germany, October 2001, p. 995-1000. 


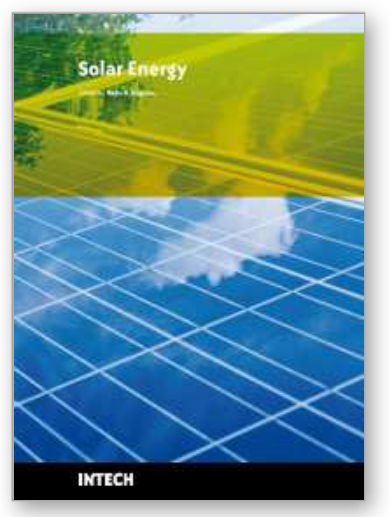

\author{
Solar Energy \\ Edited by Radu D Rugescu
}

ISBN 978-953-307-052-0

Hard cover, 432 pages

Publisher InTech

Published online 01, February, 2010

Published in print edition February, 2010

The present "Solar Energy" science book hopefully opens a series of other first-hand texts in new technologies with practical impact and subsequent interest. They might include the ecological combustion of fossil fuels, space technology in the benefit of local and remote communities, new trends in the development of secure Internet Communications on an interplanetary scale, new breakthroughs in the propulsion technology and others. The editors will be pleased to see that the present book is open to debate and they will wait for the readers' reaction with great interest. Critics and proposals will be equally welcomed.

\title{
How to reference
}

In order to correctly reference this scholarly work, feel free to copy and paste the following:

Leonid Kosyachenko (2010). Efficiency of Thin-Film CdS/CdTe Solar Cells, Solar Energy, Radu D Rugescu (Ed.), ISBN: 978-953-307-052-0, InTech, Available from: http://www.intechopen.com/books/solarenergy/efficiency-of-thin-film-cds-cdte-solar-cells

\section{INTECH}

open science | open minds

\author{
InTech Europe \\ University Campus STeP Ri \\ Slavka Krautzeka 83/A \\ 51000 Rijeka, Croatia \\ Phone: +385 (51) 770447 \\ Fax: +385 (51) 686166 \\ www.intechopen.com
}

\author{
InTech China \\ Unit 405, Office Block, Hotel Equatorial Shanghai \\ No.65, Yan An Road (West), Shanghai, 200040, China \\ 中国上海市延安西路65号上海国际贵都大饭店办公楼405单元 \\ Phone: +86-21-62489820 \\ Fax: +86-21-62489821
}


(C) 2010 The Author(s). Licensee IntechOpen. This chapter is distributed under the terms of the Creative Commons Attribution-NonCommercialShareAlike-3.0 License, which permits use, distribution and reproduction for non-commercial purposes, provided the original is properly cited and derivative works building on this content are distributed under the same license. 